\title{
NMR-compatible Sample Cell for Gas Hydrate Studies in Porous Media
}

\author{
Abraham Rojas Zuniga, Ming Li, Zachary M. Aman, Paul L. \\ Stanwix, Eric F. May, Michael L. Johns* \\ Department of Chemical Engineering, School of Engineering, The University of \\ Western Australia, Crawley, WA 6009, Australia. \\ *Corresponding author \\ Email: michael.johns@uwa.edu.au
}




\begin{abstract}
The production of methane $\left(\mathrm{CH}_{4}\right)$ from natural-gas hydrate deposits via molecular replacement by injected, thermodynamically more favourable, carbon dioxide $\left(\mathrm{CO}_{2}\right)$ is a promising method of energy production and carbon sequestration. However, the viability of this technique is constrained by mass-transfer limitations, which are in turn associated with diffusion of the injected $\mathrm{CO}_{2}$ into the hydrate-bearing sediment layers. Generally, the coupled heat- and mass-transfer phenomena associated with this replacement process in a complex heterogeneous porous media, are poorly understood. In order to facilitate the non-invasive pore-scale study of this replacement process (ultimately in sediment cores) using a range of Nuclear Magnetic Resonance (NMR) and Magnetic Resonance Imaging (MRI) techniques, a novel NMR-compatible sediment holder has been designed and constructed. Via the provision of centralised sample cooling, sample temperature control is afforded at high pressures whilst keeping the NMR magnet system at the required temperature. Hydrate formation and dissociation processes in model porous media were successfully investigated using a $\mathrm{CH}_{4} / \mathrm{C}_{2} \mathrm{H}_{6}$ mixture and $\mathrm{CO}_{2}$ respectively. Novel 1D MRI images of the residual liquid water and hydrocarbon gas were acquired during the hydrate formation and dissociation processes using a SPRITE MRI pulse sequence. Interleaved NMR $T_{2}$ relaxation measurements were also obtained to interrogate the pores sizes occupied by the residual water. From these results, the water distribution and subsequent hydrate-formation behaviour has been spatially and temporally resolved throughout the porous media.
\end{abstract}

Key words: porous media sample holder, hydrates, NMR, MRI, Finite Element Modelling 


\section{INTRODUCTION}

Natural gas hydrates (NGHs) have been widely recognised as a vast hydrocarbon resource with an energy content much greater than that in all remaining conventional fossil fuels. ${ }^{1-3}$ Gas hydrates are ice-like crystalline solids that occur when water and suitably sized gas molecules (typically less than $9.0 \AA$ in diameter) are combined at high pressure and low temperature conditions. ${ }^{4}$ In nature, these hydrates form vast repositories of natural gas in both deep ocean sediment and shallow strata at depths ranging from 300 to $4000 \mathrm{~m}$, where relevant thermodynamic conditions exist with a sufficient source of biogenic or thermogenic gases. ${ }^{5}$ As the world moves from liquid and solid fuels to a greater use of natural gas, the attractiveness of these NGHs is enhanced as a prospective energy resource. ${ }^{6}$ However, their viable development is still economically and technologically challenging.

The injection of carbon dioxide $\left(\mathrm{CO}_{2}\right)$ offers the possibility to recover natural gas from hydrate reservoirs via $\mathrm{CH}_{4}-\mathrm{CO}_{2}$ exchange with beneficial implications for $\mathrm{CO}_{2}$ sequestration. In this process, high pressure $\mathrm{CO}_{2}$ replaces $\mathrm{CH}_{4}$ as the guest molecule in the hydrate crystal structure. Whilst this replacement process is thermodynamically favourable under a range of relevant conditions, and has been demonstrated on both a laboratory and field scale, ${ }^{7,8}$ the commercial viability of this production technique is poor on account of limited $\mathrm{CO}_{2}$ injectivity resulting in low $\mathrm{CH}_{4}$ recovery rates. ${ }^{9}$ Mass transfer limitations, as conversion proceeds, are key and manifest as supercritical $\mathrm{CO}_{2}$ being unable to substantially penetrate the product $\mathrm{CO}_{2}$ hydrate surface to access the underlying natural gas hydrates. This mass transfer is clearly a function of a range of factors including hydrate distribution, permeability, porosity, as well as the pore space heterogeneity and wettability of the host sediments. Nonetheless, a detailed quantitative understanding of the replacement mechanism is still somewhat elusive. ${ }^{10}$ Extensive reviews of current knowledge regarding the properties and kinetics of the replacement reaction are provided by Komatsu et al. ${ }^{11}$ and Koh et al. ${ }^{12}$

Non-invasive interrogation of this replacement process is possible using a range of tomographic techniques. ${ }^{13-15}$ Here, we focus on the application of nuclear magnetic resonance (NMR) and magnetic resonance imaging (MRI) methods. These have been widely applied across porous media studies, in particular with respect to petro-physics. ${ }^{16,17}$ In order to facilitate such studies at relevant reservoir conditions, the use of a variety of rock core holders which are 
compatible with NMR/MRI hardware has been reported. ${ }^{18-22}$ Located within NMR/MRI magnet systems, these holders are generally required to be constructed from non-metallic materials. In this regard, high-strength polymers (e.g. PTFE, PEEK and Polyimide) are typically employed. ${ }^{19,20,22}$ In the current application, the need for sub-zero sample cooling is significant in order for the required hydrates to form within a given porous media. This must be achieved whilst ensuring the surrounding magnet's temperature is tightly controlled at the required operational set point of, in our case, $35^{\circ} \mathrm{C}$.

In this work, we present the design and construction of a new NMR-compatible sample holder, which is suitable for low-field benchtop NMR hardware as is widely used in the context of rock core characterisation. Given the required formation of hydrates within a sediment bed, refrigerative cooling is provided to the sample from a central cylindrical channel, which when coupled with silica aerogel insulation minimises any thermal influence on the surrounding magnets in the NMR/MRI system. The mechanical design of the (predominately PEEK) sample holder as a function of temperature is interrogated using 3-D finite element method (FEM) simulations. ${ }^{23,24}$ By way of validation, hydrate formation and dissociation processes are subsequently studied using both a methane/ethane mixture and $\mathrm{CO}_{2}$. MRI 1D profiles are shown to be able to track the temporal evolution in the free water content through these processes, whilst NMR $T_{2}$ measurements are used to probe the evolution in the pore size distribution occupied by this free residual water. These collectively facilitate the future application of this hydrate sample holder to $\mathrm{CH}_{4}-\mathrm{CO}_{2}$ hydrate exchange experiments.

\section{BACKGROUND}

\subsection{Relevant NMR and MRI Theory}

In the oil and gas industry, NMR relaxation measurements are routinely applied for reservoir characterization through both rock core analysis in the laboratory (occasionally at reservoir conditions) and well logging programs in the field. ${ }^{25}$ These non-invasive measurements often consider the measured ${ }^{1} \mathrm{H}$ NMR signal transverse relaxation times $\left(T_{2}\right)$. In particular, the derived probability distributions of $T_{2}, P\left(T_{2}\right)$, are commonly utilized to estimate petro-physical properties such as porosity, permeability, pore size distribution and wettability. ${ }^{17,26}$ The NMR signal intensity $M(t)$ is acquired using a standard Carr-Purcell-Meiboom-Gill (CPMG) pulse sequence ${ }^{27}$ and fit with the following expression to determine $P\left(T_{2}\right)$ : 


$$
\frac{M(t)}{M_{0}}=\int P\left(T_{2}\right) \exp \left(-\frac{t}{T_{2}}\right) d T_{2}
$$

where $M(\mathrm{t})$ is the measured signal intensity at time $t$ and $M_{0}$ is the initial magnetization at $t=$ 0 .

In the absence of significant diffusion through gradients in the magnetic field, the measured value of $T_{2}$ can be expressed as follows: ${ }^{28}$

$$
\frac{1}{T_{2}} \approx \frac{1}{T_{2 \mathrm{~B}}}+\frac{1}{\mathrm{~T}_{2 \mathrm{~S}}}
$$

where $T_{2 \mathrm{~B}}$ is the bulk relaxation time of the relevant fluid and $T_{2 \mathrm{~S}}$ is the surface relaxation time. For fluids inside porous media, $T_{2 \mathrm{~S}}$ can be expressed as follows: ${ }^{29,30}$

$$
\frac{1}{T_{2 S}}=\rho_{2}\left(\frac{S}{V}\right)
$$

Here, $\rho_{2}$ is the transverse surface relaxivity and $(S / V)$ represents the surface-to-volume ratio of the pore space. $T_{2 \mathrm{~B}}$ is usually much longer than $T_{2 \mathrm{~S}}$, consequently it can be assumed that $1 / T_{2}$ is equivalent to $1 / T_{2 \mathrm{~S} .}{ }^{16} \mathrm{~A}$ relationship can then be established between pore size and $T_{2}$ assuming the confining geometry to be perfectly spherical with a radius, $r$ :

$$
\frac{1}{T_{2}} \approx \rho_{2}\left(\frac{3}{r}\right)
$$

MRI techniques have found moderate application for the characterization of porous materials via determination of spatially-resolved fluid saturations in porous media. ${ }^{16,31}$ In order to follow dynamic processes occurring between fluids contained within a porous medium, onedimensional (1D) MRI measurements or axial profiles have been used to monitor displacement processes. $^{22,32}$ The most common approach is to employ a standard spin echo MRI method for such profiling purposes. ${ }^{33,34}$ However Single-Point Ramped Imaging with $T_{1}$ Enhancement $(\text { SPRITE })^{35}$ has been developed and proven to be more immune to NMR r.f. imperfections and signal relaxation effects, providing more quantitative rock fluid MR images than the spin echo 
method. ${ }^{22}$ In this work, 1D SPRITE MRI measurements were employed to monitor the fluid signal (liquid water or hydrocarbon gases) during gas hydrate generation and dissociation processes.

\subsection{NMR Studies of Hydrate Systems}

Most NMR studies of gas hydrates in the literature employ high field NMR equipment. Solid-state NMR spectroscopy has been used to determine hydrate structure type and relative cage occupancies of various hydrate-former molecules. ${ }^{12}$ Solid-state ${ }^{13} \mathrm{C}$ NMR spectra measurements were used to determine the phase equilibria of gas hydrates formed with $\mathrm{CO}_{2}$ and $\mathrm{CH}_{4}$ within heterogeneous porous materials. ${ }^{36,37}$ These studies showed that the hydrate phase equilibrium was shifted to larger pressure values due to capillary effects. Lee et al. ${ }^{38}$ conducted $\mathrm{CO}_{2}$ replacement experiments through silica gel samples and developed a method based on solid-state ${ }^{13} \mathrm{C}$ NMR spectroscopy to estimate the expected $\mathrm{CH}_{4}$ recovery and $\mathrm{CO}_{2}$ concentrations in the hydrate phase after the substitution process. Cha et al. ${ }^{39}$ employed both in situ ${ }^{1} \mathrm{H}$ and ${ }^{13} \mathrm{C}$ NMR spectroscopy to monitor the replacement kinetics in methane hydrates when subjected to mixtures of $\mathrm{CO}_{2}$ and $\mathrm{N}_{2}$. A spontaneous exchange reaction was suggested, as there was no evidence of increased ${ }^{1} \mathrm{H}$ NMR signal due to the formation of free water molecules. Additionally, the replacement ratio was observed to slightly increase for the smallest hydrate cages, which may be attributed to the presence of $\mathrm{N}_{2}$. The replacement process for mixed hydrate crystals ( $\mathrm{sII}$ and $\mathrm{sH}$ ) using $\mathrm{CO}_{2}$ has also been systematically studied using a combination of ${ }^{13} \mathrm{C}$ NMR and various other metrology modalities. ${ }^{40-42}$

The application of MRI methods for the study of visually opaque hydrates systems is comparatively less mature. Baldwin et al. ${ }^{43}$ imaged the spatial distribution of THF hydrates in rock cores during hydrate formation/dissociation experiments. Using MRI measurements, Bagherzadeh et al. ${ }^{44}$ found that hydrate formation occurs at a uniform rate within unconsolidated sediment independent of grain size employed. By analysing the variations in the MRI signal intensity, Huseb $\varnothing$ et al. $^{45}$ investigated the effects of salinity on the thermodynamic stability of $\mathrm{CH}_{4}$ hydrates in rock cores. It was observed that $\mathrm{CH}_{4}$ hydrate saturation was controlled by the total brine salinity rather than brine distribution within the pore network. Focused on $\mathrm{CO}_{2}$ storage in NGH deposits, Kvamme et al. ${ }^{46,47}$ employed MRI to monitor free water and hence permeability reduction while $\mathrm{CO}_{2}$ hydrates were formed in various sandstones. Ersland et al. ${ }^{18,48}$ provided tomographic evidence regards the conversion of $\mathrm{CH}_{4}$ hydrates into $\mathrm{CO}_{2}$ hydrates within a Bentheimer sandstone core plug. These 
tomographic images resolved the liquid water distribution and indicated that little hydrate dissociation was occurring during the $\mathrm{CH}_{4}-\mathrm{CO}_{2}$ exchange process. Song et al. ${ }^{49}$ imaged water distributions in a porous medium during NGH dissociation as pressure was decreased and temperature was increased.

In addition to NMR spectroscopy and MRI, the use of NMR relaxometry has also been applied in various studies of hydrate systems relevant to $\mathrm{CO}_{2}-\mathrm{CH}_{4}$ exchange. Kleinberg et al. ${ }^{28 \text {, }}$

${ }^{50}$ for example, showed the applicability of NMR relaxometry in permafrost and deep ocean sediments to evaluate various petro-physical properties such as pore size, permeability and phase saturations (hydrate, water, free gas). Minagawa et al. ${ }^{51,52}$ estimated both the pore size distribution and permeability of hydrate-bearing sandstones whilst Komai et al. ${ }^{53}$ assessed the reduction in porosity and permeability as methane hydrate formed in various sandstones. Recently, 2D $T_{1}-T_{2}$ NMR measurements have been conducted to resolve different phase compositions in a variety of porous media during hydrate generation and dissociation in porous media. $^{54,55}$

\section{MATERIALS AND METHODS}

\subsection{Materials}

Figure 1 shows the NMR-compatible hydrate sample holder designed and constructed in this work. This cylindrical sample holder has a $46 \mathrm{~mm}$ outer diameter, $34 \mathrm{~mm}$ inner diameter, and a length of $163 \mathrm{~mm}$. This cell readily fits inside desktop NMR spectrometers that are routinely used for rock core analysis, and can accommodate a sample volume of $56 \mathrm{~mL}$. In the current application, it was accommodated within a benchtop Oxford Maran Ultra $12.9 \mathrm{MHz}$ rock core analyser from Oxford Instruments, UK. 

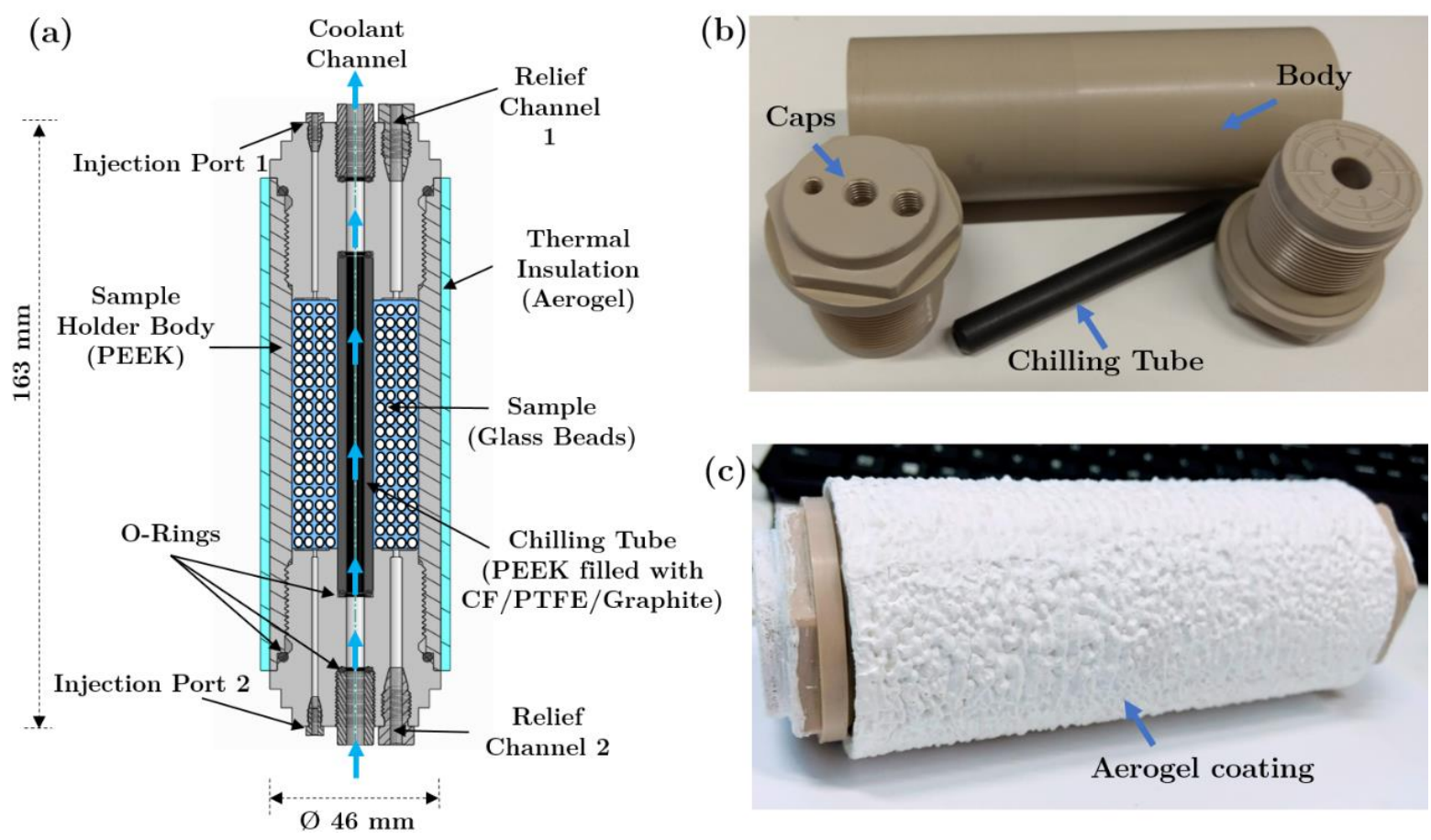

Figure 1. NMR-compatible hydrate sample holder. (a) Cross-sectional schematic of the sample holder assembly, showing the assembly of the middle chilling tube and the fluid flow channels through the end-caps (b) Photograph of the hydrate sample holder without thermal insulation, and (c) complete assembly with an aerogel coating for thermal insulation.

The hydrate sample holder requires two end-caps to seal the sample, these include three connections which provide access for the process fluid inlet/outlet, safety pressure relief and the inner coolant fluid respectively (Figure 1.a). The core holder body and the end-caps were constructed using Polyether-ether-ketone (PEEK) (E-Plas, Western Australia, Australia), which is NMR compatible, as well as reasonably wear and chemical resistant. Internal to the core holder is a chilling tube with the following dimensions: $9.53 \mathrm{~mm} \mathrm{OD}, 4.76 \mathrm{~mm} \mathrm{ID}$, and $90.55 \mathrm{~mm}$ length (Figure 1.b). This connects concentrically to both end-caps and it is made from a reinforced PEEK matrix (Ensinger, Nufringen, Germany), which is a composite of PEEK, carbon fibre (CF), (PTFE) and graphite. This modified PEEK composite was selected as it has an improved thermal conductivity $\left(0.82 \mathrm{~W} \mathrm{~m}^{-1} \mathrm{~K}^{-1}\right)$ relative to standard PEEK $(0.28$ $\mathrm{W} \mathrm{m} \mathrm{m}^{-1} \mathrm{~K}^{-1}$ ). The chilling tube allows for coolant at atmospheric pressure to be circulated through the core holder and thus for the provision of cooling from its central region. The 
coolant mixture used consisted of an equal volume of water and ethylene-glycol ${ }^{1}$ (ChemSupply, SA, Australia) dosed with $1.68 \mathrm{wt} \%$ Manganese chloride $\left(\mathrm{MnCl}_{2}\right)$, which served as a paramagnetic agent to eliminate the ${ }^{1} \mathrm{H}$ NMR signal from the mixture. $\left(\mathrm{MnCl}_{2}\right.$ decreased the ${ }^{1} \mathrm{H}$ NMR $T_{2}$ of the mixture from $1 \mathrm{~s}$ to $0.0008 \mathrm{~s}$ at which point it is practically undetectable in the experiments conducted). The physical interfaces between the cooling tubing and the endcaps, as well as the seal between the main core holder body and the end-caps used Kalrez Orings (Dupont, $\mathrm{TN}, \mathrm{USA}$ ) which are $\mathrm{CO}_{2}$ compatible as required. The final assembly is able to accommodate sample pressures up to at least 100 bar.

The outside of the core holder is treated and coated with thermally insulating silica aerogel (Tec Corporation LTD, Korea) to an average thickness of $2.5 \mathrm{~mm}$ (Figure 1.c) The provision of internal cooling coupled with this thermal insulation allowed for adequate temperature control of the surrounding magnet assembly at the required temperature of $35^{\circ} \mathrm{C}$. The aerogel coating also serves to reduce condensation on the core holder, this was further reduced by a continuous flow of dry air over the aerogel layer during experiments - this also served to assist in magnet temperature regulation.

To form gas hydrates in the sample holder, deionized water was used along with two different gas hydrate formers: (1) a mixture of methane and ethane (molar fractions: $x_{\mathrm{CH}_{4}}=$ 0.68 and $x_{C_{2} H_{6}}=0.32$ ); and (2) $\mathrm{CO}_{2}$ (both supplied by Coregas at purities of 99.995\%). The model host porous media used was a random packing of spherical glass ballotini, comprising a grain size distribution from $500 \mu \mathrm{m}$ to $850 \mu \mathrm{m}$ (with a mean diameter of $660 \mu \mathrm{m}$ ) and a gravimetrically determined porosity of $36 \%$. It had a density of $\sim 2.4 \mathrm{~g} \mathrm{~cm}^{-3}$, and a thermal conductivity of $1.09 \mathrm{Wm}^{-1} \mathrm{~K}^{-1} .99$

\subsection{Experimental Setup}

The complete experimental apparatus is schematically shown in Figure 2. This system involves two flow loops:

${ }^{1}$ In traditional core flooding a per-fluorinated compound is usually employed, however a waterMEG mixture was selected in this case as it presents an approximately 10 -fold increase in thermal conductivity $\left(\sim 0.40 \mathrm{~W} \mathrm{~m}^{-1} \mathrm{~K}^{-1},{ }^{56}\right.$ versus $\left.\sim 0.057 \mathrm{~W} \mathrm{~m}^{-1} \mathrm{~K}^{-1},{ }^{57,58}\right)$. 
(1) The high-pressure sample fluid, which enables the direct injection of relevant fluids to the sample using the end-cap injection ports. The porous media sample (glass ballotini packing) was placed in the core holder around the central chilling tubing. Following this, sample fluids (water, $\mathrm{CO}_{2}$ or $\mathrm{CH}_{4} / \mathrm{C}_{2} \mathrm{H}_{6}$ mixture) were circulated through the core holder under high pressure using two syringe pumps (Teledyne ISCO Pump 260D, USA). Two pressure relief valves were included in the high-pressure flow loop such that a maximum working pressure of 100 bar was not exceeded.

(2) The atmospheric pressure coolant mixture via the central chilling tube. The coolant mixture was pumped through the chilling tubing using a thermostatic bath (Lauda Alpha RA8, Germany) at a flowrate of $15 \mathrm{~L} / \mathrm{min}$.

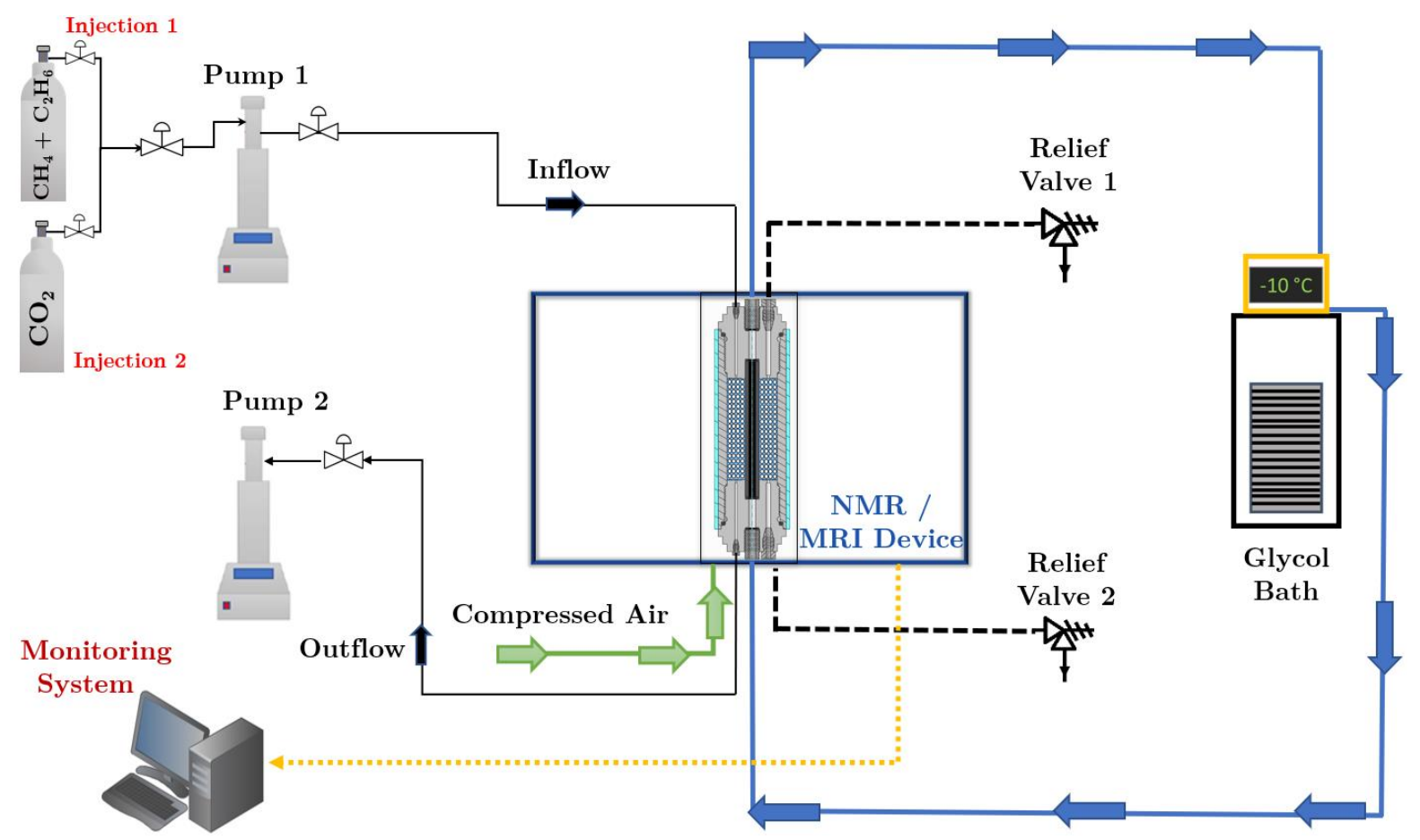

Figure 2. Schematic of the complete experimental apparatus for gas hydrate formation/dissociation monitored by NMR and MRI measurements. Two distinct flow loops are used for the sample fluid (high pressure) and the cooling fluid (atmospheric pressure) respectively.

\subsection{Thermomechanical Analysis of the new Sample Holder}

Given the use of different materials of construction and the use of high pressure and low temperatures, the following mechanical analysis of the sample holder was completed. A geometrically consistent $3 \mathrm{D}$ model for the sample holder was developed in Solidworks ${ }^{\mathrm{TM}}$ (Dassault Systems, France). Subsequently, the thermal and mechanical response of the core holder to high pressure and low temperature regimes was numerically simulated using ANSYS Multiphysics $^{\mathrm{TM}}$ (ANSYS, USA). The required material mechanical and thermal properties are 
listed in Table 1. Finite element modelling (FEM) was used to determine the coupled induced stresses and temperature distribution within the core holder in $3 \mathrm{D}$ as a function of temperature and pressures (covering a range from 40 to 100 bar and 10 to $-25^{\circ} \mathrm{C}$, respectively).

Table 1. Principal properties of materials employed in the 3D FEM Model

\begin{tabular}{llccccc}
\hline Component & Material & $\begin{array}{c}\text { Density } \\
{\left[\mathbf{g} / \mathbf{c m}^{3}\right]}\end{array}$ & $\begin{array}{c}\text { Thermal } \\
\text { Conductivity } \\
{[\mathbf{W} / \mathbf{m} \mathbf{K}]}\end{array}$ & $\begin{array}{c}\text { Young's } \\
\text { Modulus } \\
{[\mathbf{M P a}]}\end{array}$ & $\begin{array}{c}\text { Tensile Yield } \\
\text { Strength } \\
{[\mathbf{M P a}]}\end{array}$ & $\begin{array}{c}\text { Elongation } \\
\text { at Break } \\
{[\%]}\end{array}$ \\
\hline Thermal Insulation & Silica Aerogel & 0.16 & $0.0442^{1}$ & - & - & - \\
Core Holder Body & PEEK & 1.32 & 0.28 & 4400 & 110 & 20 \\
End-Caps & PEEK & 1.32 & 0.28 & 4400 & 110 & 20 \\
$\begin{array}{l}\text { Sample } \\
\text { (Porous Medium) }\end{array}$ & Glass Ballotini & 2.23 & $0.2-0.36^{2}$ & - & - & - \\
Chilling Tubing & $\begin{array}{l}\text { PEEK } \\
\text { Composite }\end{array}$ & 1.44 & 0.82 & 5500 & 102 & 3 \\
\hline
\end{tabular}

1. The thermal conductivity of the aerogel estimated for a layer with $2.5 \mathrm{~mm}$ of thickness.

2. This range corresponds to the sample volume being fully saturated with air or water. The temperature profile was relatively insensitive to this range $\left(<0.9^{\circ} \mathrm{C}\right)$

Temperature distribution results are shown in Figure 3. A 3D simulation of the temperature distribution through the sample space is shown in Figure 3(a) for the case when the coolant mixture is at $-25{ }^{\circ} \mathrm{C}$ and the sample is fully water-saturated. The external temperature of the sample holder is consistently above $20{ }^{\circ} \mathrm{C}$, which is adequate for temperature control of the surrounding magnet. The sample can readily reach temperatures down to $-5{ }^{\circ} \mathrm{C}$. Figure $3(\mathrm{~b})$ shows the mean sample temperature, as predicted by the simulation platform, as a function of the coolant temperature recorded at the glycol bath. (Note that the coolant temperature will rise prior to entering the sampler holder cooling tube - this is minimised to less than $5{ }^{\circ} \mathrm{C}$ via extensive insulation on the supply line.) Validation measurements of the sample temperature were also performed as a function of coolant temperature using a RS PRO Digital Thermometer inserted into the sample volume of the holder through one of the injection ports (this was done outside of the magnet environment). The corresponding data are also plotted in Figure 3(b) there is excellent agreement with the simulation predictions across the temperature range considered with a maximum discrepancy of $0.8^{\circ} \mathrm{C}$. 
(a)

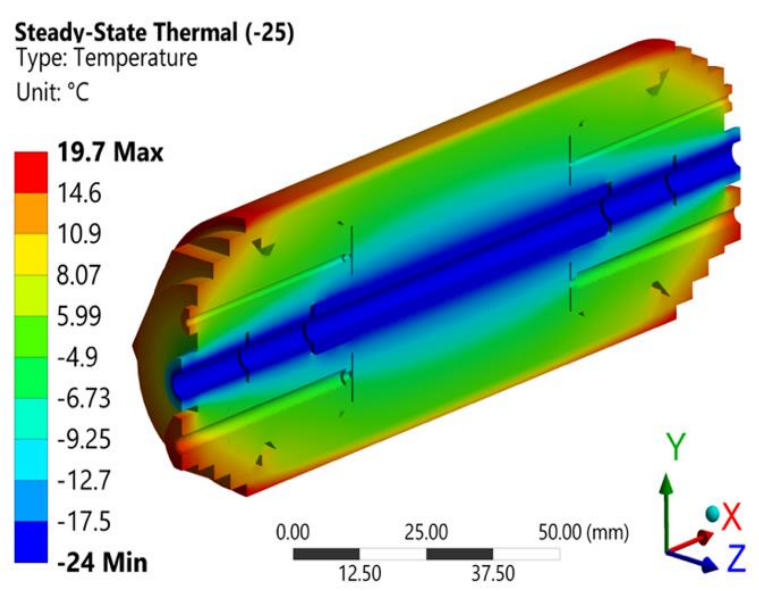

(b)

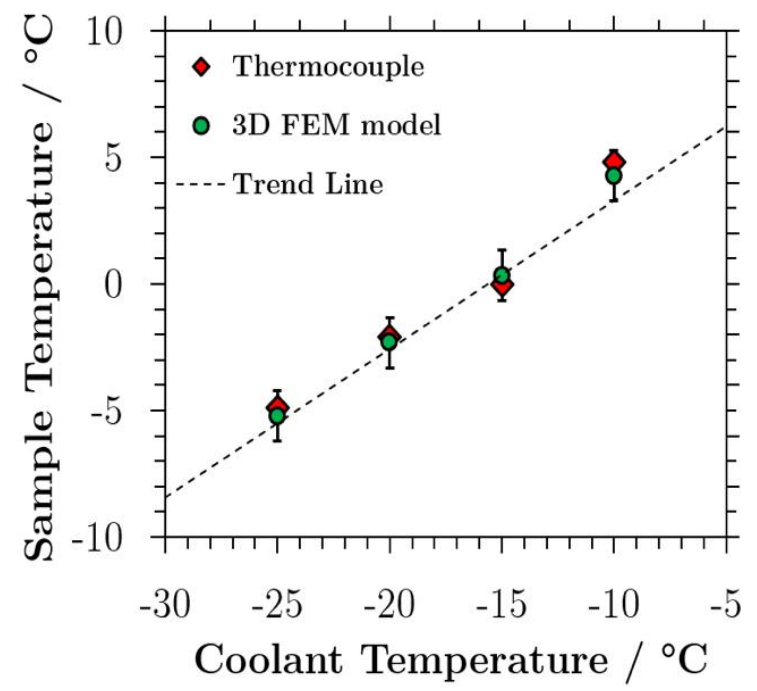

Figure 3 (a) Thermal simulation using 3D FEM model of the sample holder using a coolant temperature of $-25^{\circ} \mathrm{C}$. (b) Sample temperature versus coolant temperature - both as predicted by the simulation and via measurement with a thermocouple located in the sample volume.

Figure 4 presents the results obtained from the mechanical simulation. Figure 4(a) shows the equivalent stress in the holder (in 3D) for the maximum working conditions (pore fluid pressure 100 bar, coolant fluid temperature $-25^{\circ} \mathrm{C}$ ) - the highest equivalent stress generated is 47.8 MPa. To assess the mechanical integrity, the ratio between the tensile yield strength of the relevant material (reported in Table 1) and the equivalent stress was calculated (hereafter referred to as the 'safety factor'). The mean safety factor for the various sample holder components is reported in Figure 4(b) as a function of pressure for a cooling fluid temperature of $-25{ }^{\circ} \mathrm{C}$. In all cases and at all locations the safety factor exceeded a value of 2.5 . In terms of elastic properties, PEEK and its composites are regarded as being comparatively susceptible. ${ }^{60}$, ${ }^{61}$ Using the 3D analysis, the resultant elastic strain in the sample holder assembly were compared against the elongation-at-break parameter for each material (as reported in Table 1) - this property reflects the ability of polymers to resist changes of shape without crack initiation. ${ }^{62}$ The $3 \mathrm{D}$ equivalent elastic strain distribution is shown in Figure 4(c) for the maximum working conditions $\left(100 \mathrm{bar},-25^{\circ} \mathrm{C}\right)$ - the maximum strain value was $0.011 \mathrm{~mm}$ $\mathrm{mm}^{-1}$ which occurs in the contact zone between the main holder body and the end-caps. The mean value of elastic strain is expressed as a \% in Figure 4(d) as a function of pressure for the various holder components - these are consistently lower than the elongation-at-break parameters listed in Table 1. 
(a)

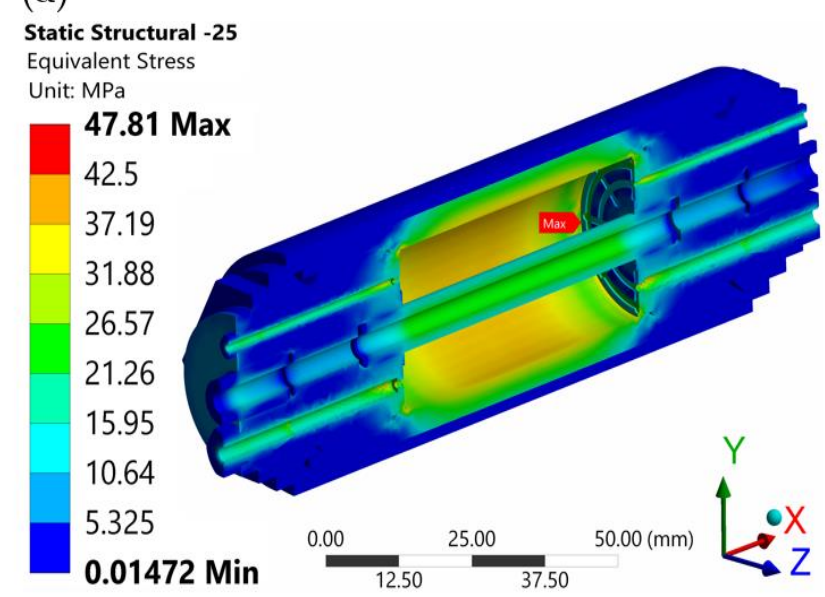

(c)

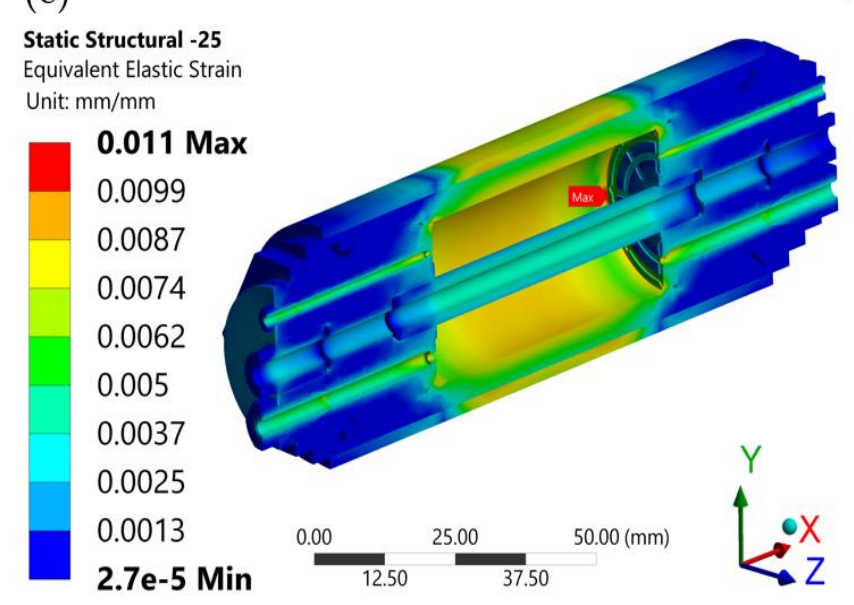

(b)

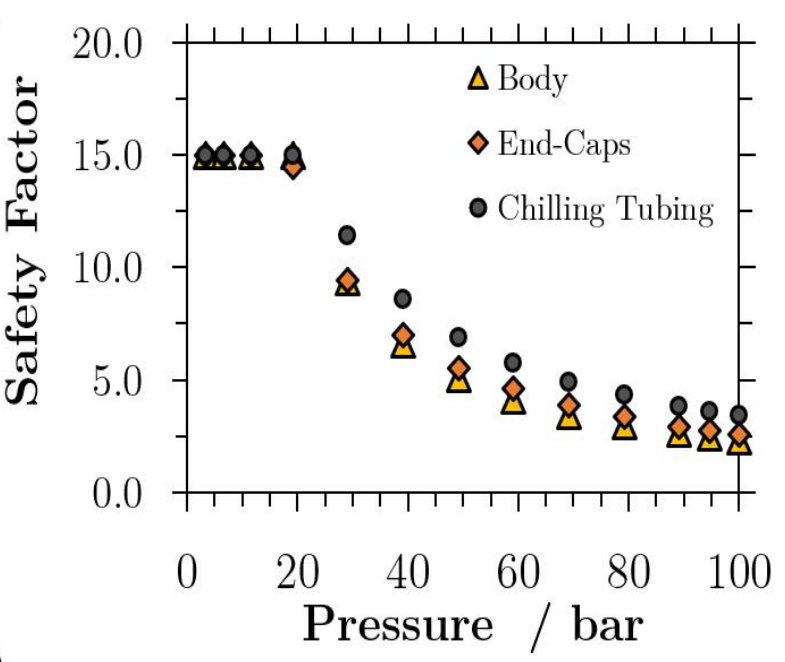

(d)

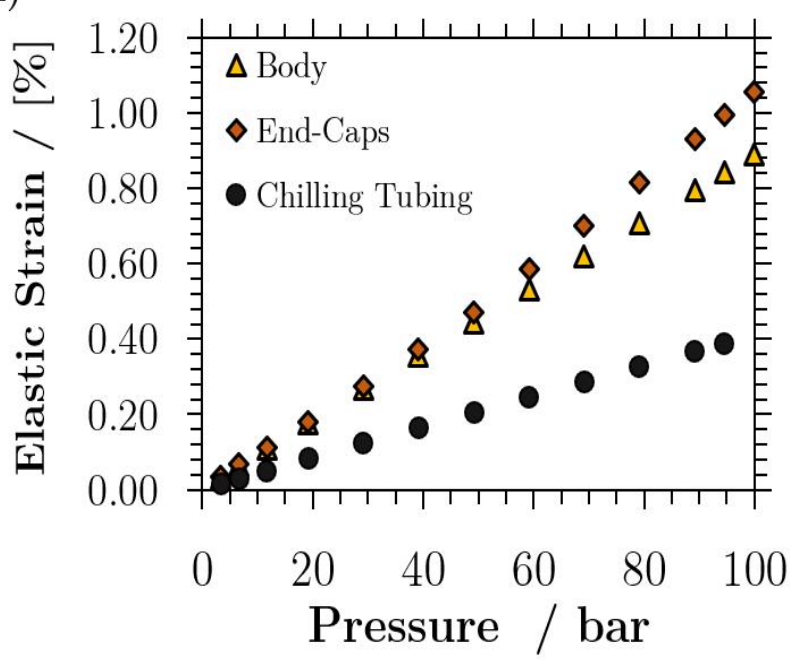

Figure 4. Structural analysis of the sample holder assembly using the 3D FEM model. (a) Equivalent stresses, according to Von Misses yield formulae. The maximum stress developed is $47.8 \mathrm{MPa}$ at $-25^{\circ} \mathrm{C}$ and 100 bar. (b) Safety factor as a function of pressures for the various components. (c) Equivalent elastic strains of the sample holder. The maximum strain was $0.011 \mathrm{~mm} \mathrm{~mm}^{-1}$, which represents a structural deformation of $0.1 \mathrm{~mm}$. (d) Equivalent elastic strain of the sample holder components as a function of pressure.

\subsection{NMR Methods Used}

A variety of interleaved NMR and MRI methodologies were employed to systematically monitor gas hydrate formation and dissociation processes in the glass ballotini packing contained within the new hydrate sample holder:

(i) Standard simple free induction decay (FID) measurements were used to determine the saturations of the different phases (water, hydrocarbon gas, and hydrate) in the ballotini packing as well as the mean value of $T_{2}{ }^{*}$ for the NMR signal bearing species. 
(ii) A standard CPMG pulse sequence ${ }^{27}$ was used to periodically determine the total signal intensity (from all ${ }^{1} \mathrm{H}$ containing fluids in the ballotini packing) as well as the probability distribution of $T_{2}$ relaxation times in the sample (which is related to the pore size distribution).

(iii) MRI measurements, specifically those using the Single Point Ramped Imaging with $T_{1}$ Enhanced (SPRITE) ${ }^{35}$ pulse sequence, were applied in $1 \mathrm{D}$ along the sample axis to determine the fluid content profile as hydrate formation and dissociation proceeded.

The experimental parameters employed in the CPMG and SPRITE acquisitions are summarised in Table 2.

Table 2. NMR and MRI measurement parameters

\begin{tabular}{lrlr}
\hline CPMG PULSE SEQUENCE & & & \\
\hline $90^{\circ}$ pulse length $(\mu \mathrm{s})$ & 14.4 & Number of averages & 16 \\
$180^{\circ}$ pulse length $(\mu \mathrm{s})$ & 29.5 & Echo time $(\mu \mathrm{s})$ & 2000 \\
Relaxation delay $(\mathrm{s})$ & 15 & Number of echoes & 4096 \\
\hline 1D SPRITE MRI & 1.5 & Total number of pixel in profile & 64 \\
\hline RF pulse length $(\mu \mathrm{s})$ & 9 & Resolution (mm) & 1.7 \\
RF pulse flip angle $(\mathrm{deg})$ & 94 & Repetition delay $(\mathrm{s})$ & 3 \\
Encoding time $(\mu \mathrm{s})$ & 10.7 & Number of averages & 64 \\
Field of view $(\mathrm{cm})$ & & & \\
\hline
\end{tabular}

\subsection{Experimental Campaign}

Initial testing of the assembled equipment utilised the formation and subsequent thawing of ice at atmospheric pressure in the water-saturated ballotini packing in the sample holder (the water content of the packing was gravimetrically determined to be $20 \mathrm{ml}$ ) whilst sequentially executing the NMR measurements detailed above. Average sample temperatures of 20, 4.0, 0.5 , and $-2.5^{\circ} \mathrm{C}$ were systematically studied by varying the temperature of the coolant mixture. Ice thawing was then realised by increasing the sample temperature back to $20{ }^{\circ} \mathrm{C}$.

Hydrate formation was then monitored in the water-saturated glass ballotini in two subsequent series of experiments using (i) $\mathrm{CO}_{2}$ and (ii) a mixture of $0.68 \mathrm{CH}_{4}+0.32 \mathrm{C}_{2} \mathrm{H}_{6}$ (mole fraction basis); water was always the limiting reactant with the relevant gas in excess. 
Water was displaced from the saturated glass ballotini packing by flowing the relevant hydrate former fluid at low pressure from above, with water allowed to freely drain from the bottom of the sample holder. In both cases, this resulted in a reduction of the water saturation from $100 \%$ to $44 \%$ (9.0 $\mathrm{ml}$ of water retained). In the case of the $\mathrm{CO}_{2}$ displacement, the pressure was then increased to 40 bar and maintained at this value throughout the experiment. Whilst repeatedly executing the series of NMR/MRI measurements detailed above, the mean sample temperature was gradually changed according to the following profile: $20^{\circ} \mathrm{C}, 3.5^{\circ} \mathrm{C}, 0{ }^{\circ} \mathrm{C},-2.2{ }^{\circ} \mathrm{C}, 3.5^{\circ} \mathrm{C}$ and $20{ }^{\circ} \mathrm{C}$, respectively. This entire measurement campaign was then repeated using the $\mathrm{CH}_{4}$ $+\mathrm{C}_{2} \mathrm{H}_{6}$ mixture as the hydrate former at a pressure of 60 bar with the following temperature profile: $20^{\circ} \mathrm{C}, 3.5^{\circ} \mathrm{C},-2.2{ }^{\circ} \mathrm{C}, 3.5^{\circ} \mathrm{C}$ and $20^{\circ} \mathrm{C}$. The conditions of these various measurement points are summarised in Figure 5 relative to their respective hydrate phase envelopes: the low temperature measurements are all comfortably within the hydrate forming region.

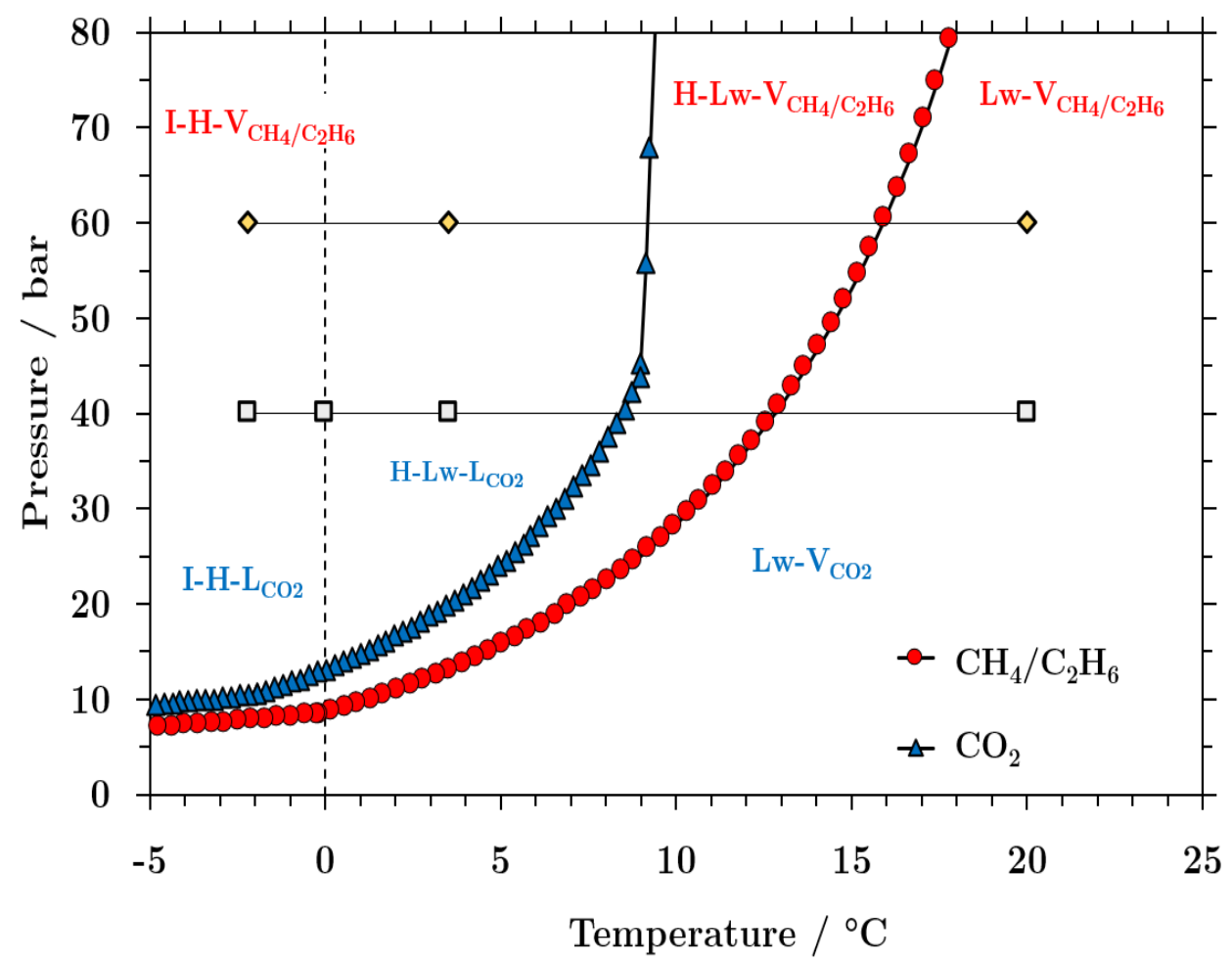

Figure 5. Hydrate phase equilibrium diagrams for a mixture of $\mathrm{CH}_{4} / \mathrm{C}_{2} \mathrm{H}_{6}$ (molar fractions $x_{\mathrm{CH}_{4}}=0.68$ and $x_{\mathrm{C}_{2} \mathrm{H}_{6}}=0.32$ ) and for pure $\mathrm{CO}_{2}$, as calculated using Multiflash ${ }^{\mathrm{TM}}$ (KBC Advanced Technologies, UK). Experimental measurement points for both $\mathrm{CH}_{4} / \mathrm{C}_{2} \mathrm{H}_{6}(\diamond)$ and $\mathrm{CO}_{2}(\square)$ are also shown. The vertical dashed lines indicates the freezing point in the absence of dissolved gas. In the case of $\mathrm{CO}_{2}$ saturation of the aqueous phase this results in a freezing point depression of $1.5^{\circ} \mathrm{C}$.

\subsection{Calculation method for phase saturations}

Phase saturations (water $\left(S_{\mathrm{w}}\right)$, gas $\left(S_{\mathrm{g}}\right)$, and hydrate $\left.\left(S_{\mathrm{hyd}}\right)\right)$ were directly determined in situ using the following series of mass balance equations: 
$H I_{\mathrm{w}} S_{\mathrm{w}}+H I_{\mathrm{g}} S_{\mathrm{g}}=I_{\mathrm{NMR}}$

$\left(\eta_{\mathrm{w}}^{t=0}-\eta_{\mathrm{w}}\right)-N \eta_{\mathrm{h}}=0$

$S_{\mathrm{w}}+S_{\mathrm{g}}+S_{\mathrm{hyd}}=1$

where $H I$ is the hydrogen index of the phase denoted by the subscript. $I_{\mathrm{NMR}}$ is the NMR signal intensity normalised to the signal intensity for the fully water saturated glass ballotini sample

$\left(S_{\mathrm{w}}=1\right)$, corrected for the influence of sample temperature. $\eta_{\mathrm{w}}^{\mathrm{t}=0}$ is the initial number of moles of water when $t=0$, prior to gas hydrate formation; $\eta_{\mathrm{w}}$ and $\eta_{\mathrm{h}}$ are the numbers of moles of water and hydrate, respectively. $N$ is the hydration number, whose value depends on the hydrate former molecule. The value reported by Subramanian et al. ${ }^{63}, N=6.62$, is used for the $\mathrm{CH}_{4} / \mathrm{C}_{2} \mathrm{H}_{6}$ hydrate whilst a value of $N=6.0$ is used for the $\mathrm{CO}_{2}$ hydrate. ${ }^{64}$

\section{RESULTS AND DISCUSSION}

\subsection{Ice validation measurements.}

Figure 6 shows the interleaved FID and CPMG NMR signal intensities (normalised to the intensity at the point of ice nucleation) for a fully saturated glass ballotini sample, as well as the mean $T_{2}{ }^{*}$ and $T_{2}$ relaxation times, as a function of time through the full freeze-thaw cycle. The corresponding mean sample temperature is also shown. In both cases the increase in NMR signal up to 7 hours can be attributed to the Boltzmann effect ${ }^{65}$ as the temperature is progressively decreased. Ice nucleation is clearly evident at 7 hours (after approximately two hours of supercooling - note NMR signal is received only from the liquid water phase) leading to rapid ice growth and consequential loss of NMR signal via both measurement protocols (CPMG and FID). Ice formation is complete after approximately 4 hours; the system is clearly heat transfer controlled. Given the thermal mass of the sample holder and the ballotini, using the 3D FEM model and the latent heat associated with ice formation we estimate that a mean overall sample temperature rise of $\sim 0.1{ }^{\circ} \mathrm{C}$ is to be expected. Residual signal is evident but is less than $2 \%$ of the original signal intensity - this will be discussed below. Increasing the temperature back to $20^{\circ} \mathrm{C}$ restored the expected NMR signal intensities.

The mean $T_{2}{ }^{*}$ is constant until the onset of nucleation at which point it increases substantially before decreasing precipitously as ice formation nears completion. $T_{2}{ }^{*}$ is very sensitive to 
background magnetic field gradients due to susceptibility differences: these are greater for water-silica as opposed to water-ice. Presumably water-ice interfaces significantly influence the $T_{2}{ }^{*}$ during initial ice growth, but water-silica interfaces dominate near the end. In contrast, the mean $T_{2}$ is observed to marginally decrease as temperature is sequentially lowered before deceasing significantly and more rapidly as ice growth occurs.
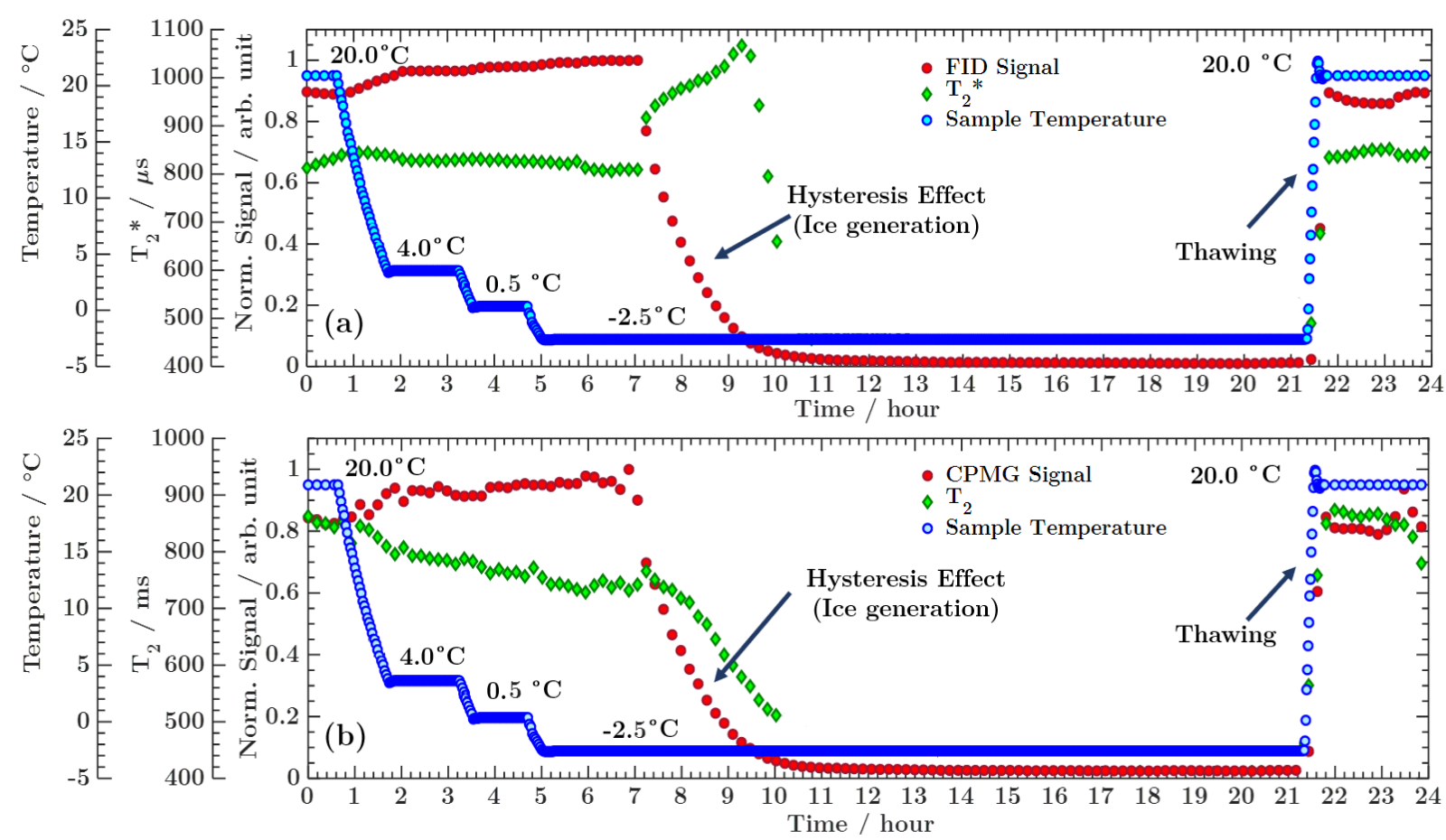

Figure 6. Ice generation and thawing test. Evolution of the (a) FID and (b) CPMG signal intensity and the mean values of the transverse relaxation times, $T_{2}{ }^{*}$ and $T_{2}$, respectively.

More instructive, however, is to consider the evolution in the distribution of $T_{2}$ relaxation times. These are shown in Figure 7(a) as a function of time. Two distinct populations are evident- these are converted to an approximate pore size using Eq. (4) and a $\rho_{2}$ value of 28.5 $\mu \mathrm{m} \mathrm{s}^{-1} .{ }^{66,67}$ The rate of ice formation (loss of signal) in both populations is approximately the same with the larger peak trending to slightly smaller $T_{2}$ values (greater confinement due to ice formation albeit the effect is minor). The small amount of residual water $(\sim 1.5 \mathrm{wt} \%, 0.3 \mathrm{ml})$ present once ice formation is complete is located in both peaks. The distributions were restored once the ice thawed. Figure 7(b) shows the signal distribution from the liquid water phase as a function of axial position and time. This distinctly shows that the residual water (once ice formation is complete) is located at both extremities of the ballotini packing in contact with the end caps. This very small amount of fluid is presumably not below $0{ }^{\circ} \mathrm{C}$ in this specific location - its relatively small size is however reassuring. The data in Figure 6 and Figure 7 provide a 
reasonable reference against which to compare the hydrate formation experiments that are now detailed.
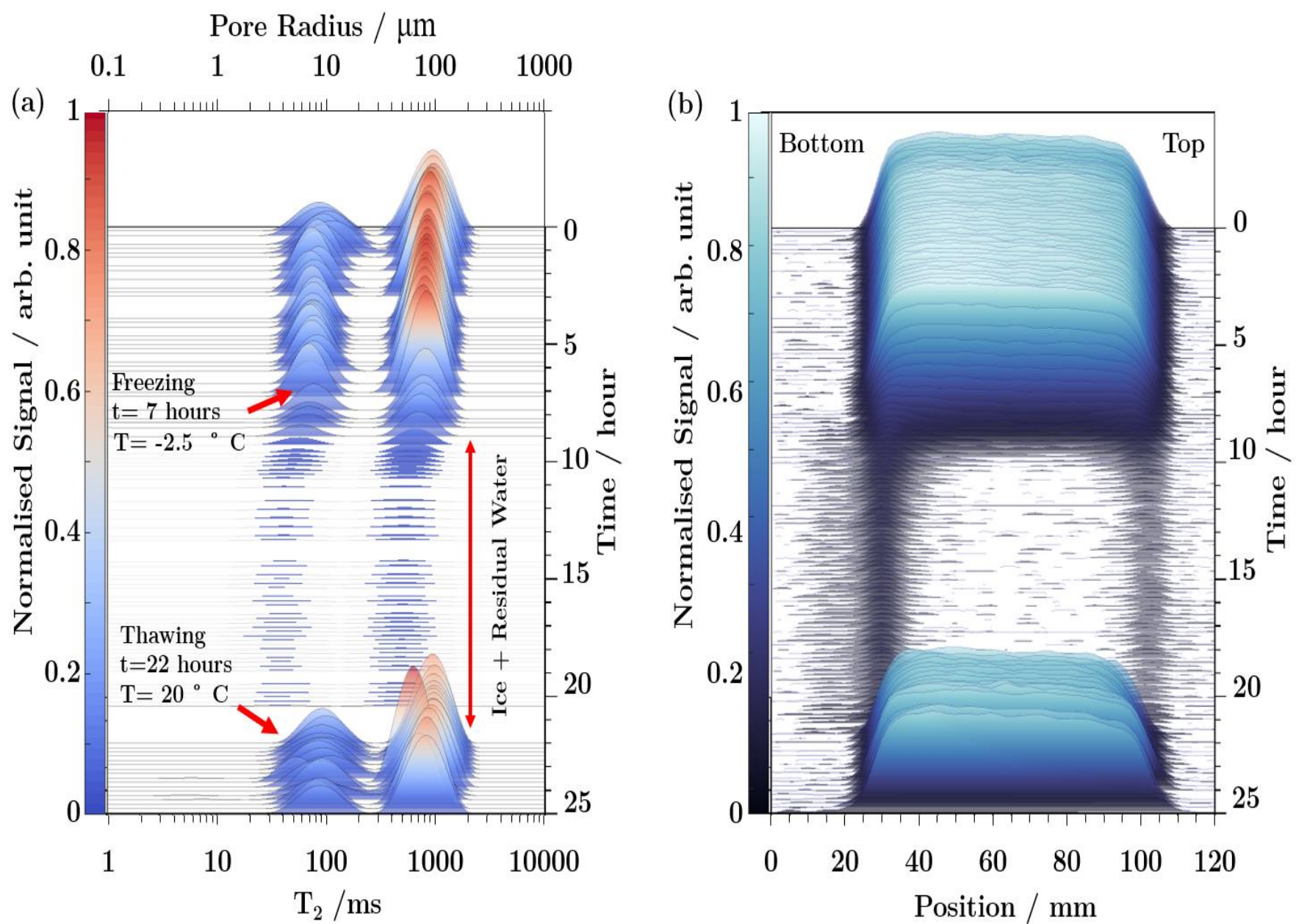

Figure 7. (a) Evolution of $T_{2}$ relaxation time distributions (and estimated pore size distribution) and (b) 1-D SPRITE profiles during ice generation and thawing in glass beads in the core holder Approximately $98 \%$ of the available water turned into ice. Ice formation and thawing process occurred similarly in all pores within the ballotini packing.

\section{$4.2 \mathrm{CO}_{2}$ Hydrate Formation and Dissociation}

After these ice validation experiments, the equivalent NMR and MRI measurements were conducted to monitor $\mathrm{CO}_{2}$ hydrate formation and dissociation. The phase saturations as a function of time, calculated using equations 5-7, are show in Figure 8. The pressure was kept at 40 bar throughout the $\mathrm{CO}_{2}$ hydrate formation and dissociation process. In this experiment, the NMR signal is solely provided by the liquid water content. 


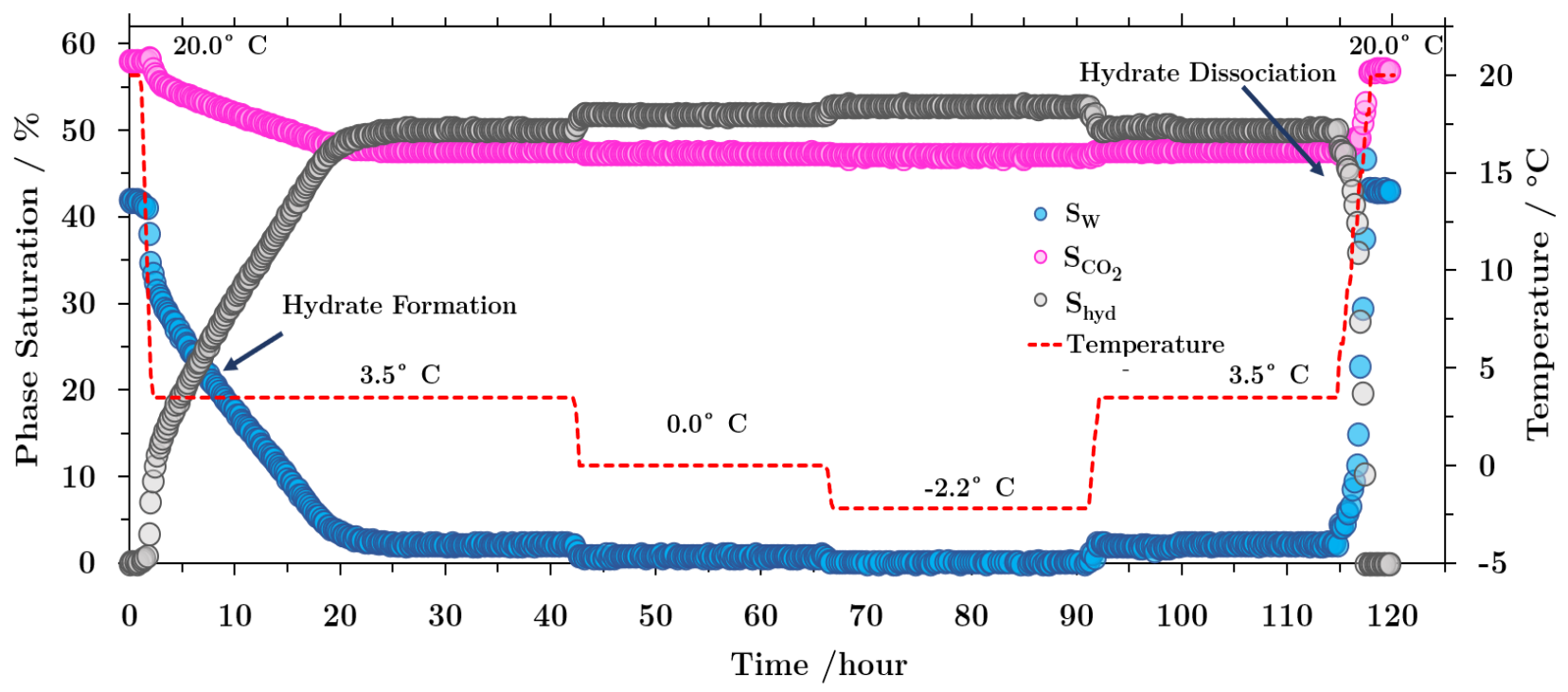

Figure 8. Phase saturations during the $\mathrm{CO}_{2}$ hydrate formation/dissociation experiment. The $\mathrm{S}_{\text {hyd }}$ increased to $50.4 \%$ when the temperature decreased to $3.5^{\circ} \mathrm{C}$ at 20 hour. Fluid saturations, $\mathrm{S}_{\mathrm{w}}$ and $\mathrm{S}_{\mathrm{CO}_{2} \text {, }}$ were $1.9 \%$ and $47.7 \%$ respectively. From 0.9 to 22.8 hour, the hydrate phase volume increased by an average rate of $0.008 \mathrm{ml} \mathrm{min}{ }^{-1}$.

Following a reduction in temperature from $20{ }^{\circ} \mathrm{C}$ to $3.5^{\circ} \mathrm{C}$, the initial water content rapidly decreased as the hydrate formation proceeded - this reached completion in $\sim 25$ hours and shows three distinct kinetic regions (rapidly between 0.9 and 2 hours, comparatively slowly between 2 and 19 hours and very slowly between 19 and 25 hours). These observations are broadly consistent with those reported by, for example, Yang et al ${ }^{68}$ who observed $\mathrm{CO}_{2}$ hydrate formation in ballotini packings at similar conditions. Only the last region presents a kinetic rate that is not constant, consistent with diffusion-limited hydrate formation control. From the water saturation value $S_{\mathrm{w}}$, approximately $25 \%$ of the water is converted to hydrate during the initial growth phase (up to 2 hours), and approximately 95\% overall (after 25 hours). The initial hydrate growth rate up to 2 hours was $0.022 \mathrm{ml} / \mathrm{min}$, which corresponds to a fractional rate of $1.1 \times 10^{-3} \mathrm{~min}^{-1}$ in terms of hydrate saturation. This then reduced to $0.006 \mathrm{ml} / \mathrm{min}\left(3 \times 10^{-4} \mathrm{~min}^{-1}\right.$ in terms of hydrate saturation) and an average of $8.47 \times 10^{-5} \mathrm{~min}^{-1}$ during the final diffusioncontrolled region. Cheng et al. ${ }^{69}$ observed an initial fractional rate of $1.6 \times 10^{-3} \mathrm{~min}^{-1}$ when performing a similar measurement; in good agreement with our data. Yang et al. ${ }^{70}$ observed an average fractional rate of $3.2 \times 10^{-3} \mathrm{~min}^{-1}$ for $\mathrm{CO}_{2}$ hydrate formation in partially saturated 100 $\mu \mathrm{m}$ ballotini whilst Yang et al. ${ }^{71}$ observed an average fractional rate of $2 \times 10^{-4} \mathrm{~min}^{-1}$ averaged over thirty hours of hydrate formation for a full saturated sand sample; again these are broadly consistent with our results. 
The residual $\mathrm{S}_{\mathrm{w}}$ value of $1.9 \%$ after hydrate formation (when the temperature was $3.5{ }^{\circ} \mathrm{C}$ ) was subtly reduced to $0.83 \%$ and $0.2 \%$ when the temperature was reduced to 0 and $-2.2{ }^{\circ} \mathrm{C}$, respectively. However the reduction from $0.83 \%$ to $0.2 \%$ is likely to reflect the formation of ice in the residual water as the $S_{\mathrm{w}}$ value is restored upon elevation of the temperature back to $3.5^{\circ} \mathrm{C}$. As discussed below, the residual $0.2 \%$ is located at the periphery of the sample holder. Note the algorithm used to allocate phase saturations from the NMR signals acquired would result in ice being erroneously allocated to the hydrate phase, as is evident in Figure 8. After approximately 115 hours the sample was warmed and the hydrate was observed to dissociate through the return of the water saturation signal. Due to temperature gradients within the cell during warming it wasn't possible to compare the dissociation temperature with the expected hydrate equilibrium.

Figure 9(a) shows the time-resolved $T_{2}$ (and estimated pore size) distribution for the residual water. The corresponding 1D axial profiles of residual water saturation are shown in Figure 9(b). In Figure 9(a), consistent with the ice formation experiment, two peaks are evident, albeit that they are less distinct. Preferential earlier $\mathrm{CO}_{2}$ hydrate formation is clearly evident in the larger pores; the distribution is fully restored upon hydrate dissociation. With respect to Figure 9(b), the effect of the initial drainage process prior to sample cooling is immediately obvious in that it has resulted in greater water accumulation in the lower portion of the ballotini packing. Note that throughout the experiment, no pressure drop was observed across the sample holder indicating that the gas phase remained well connected. Initial hydrate formation is distinctly more rapid in the bottom of the sample holder (as shown in Figure 9(c)). This we attribute to the significantly larger water saturation, resulting in a larger local thermal conductivity. This is consistent with the observation of heat transfer control as discussed above. Residual water is observed to be evenly distributed through the ballotini packing upon the completion of hydrate formation ( 25 hours). The residual water left at sub-zero temperatures (commencing after 67 hours) is again observed to form at the axial edges of the sample volume, consistent with the ice validation experiments discussed above. 


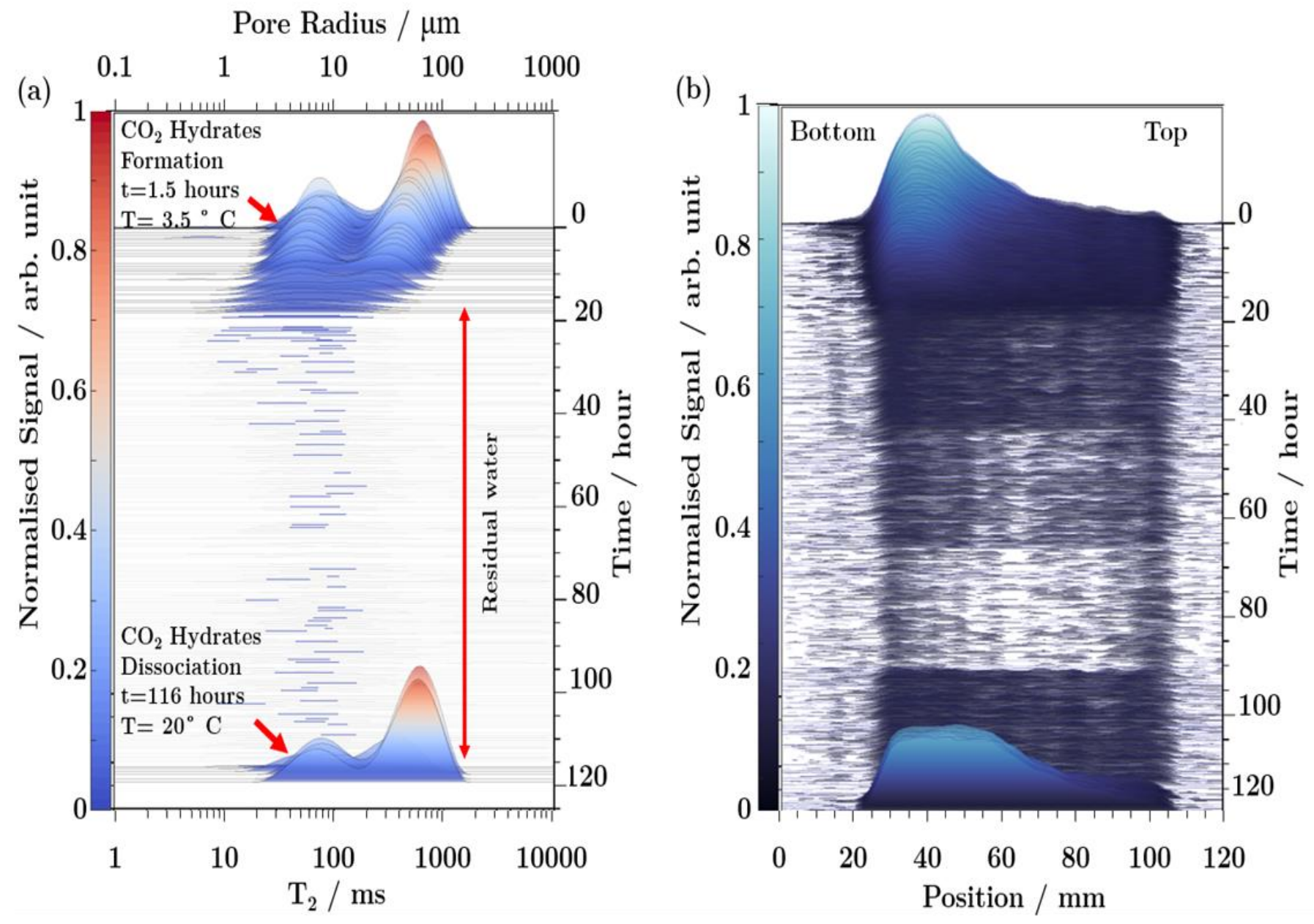

(c)

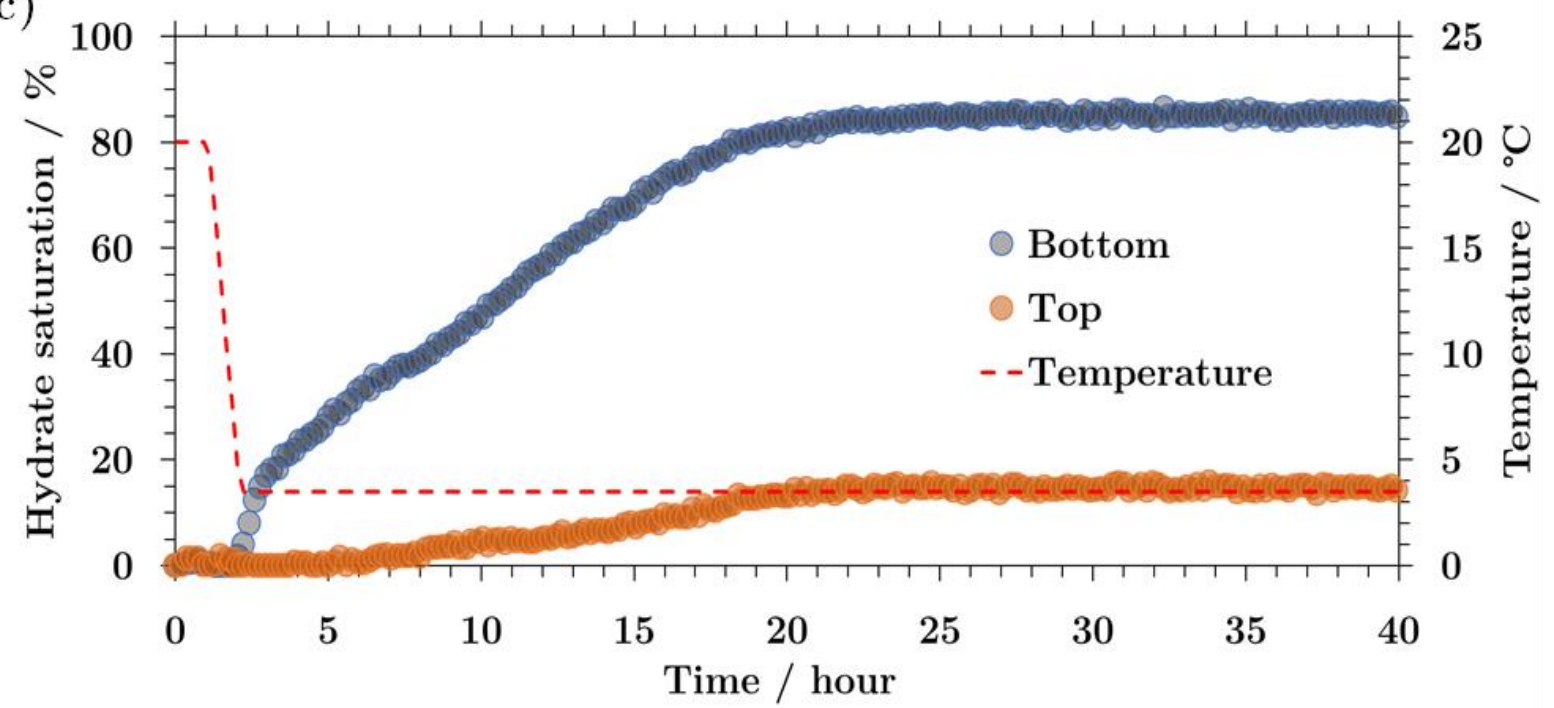

Figure 9. (a) Evolution of $T_{2}$ relaxation time (and approximate pore size) distributions and (b) 1-D SPRITE MRI profiles of residual water saturation during the $\mathrm{CO}_{2}$ hydrate formation/dissociation experiment. (c) Based on Figure 9(b), the change in hydrate saturation in the bottom and top $40 \%$ of the sample holder as a function of time. 


\section{$4.3 \mathrm{CH}_{4}+\mathrm{C}_{2} \mathrm{H}_{6}$ Hydrate Formation and Dissociation}

Figure 10 shows the phase saturations (water, gas and hydrate) through the hydrate formation /dissociation experiment conducted using a mixture of $0.68 \mathrm{CH}_{4}+0.32 \mathrm{C}_{2} \mathrm{H}_{6}(\mathrm{~mol}$ fraction) in the partially water saturated glass ballotini packing as a function of time. The temperature profile in the sample is superimposed. The pressure was kept at 60 bar throughout the experiment. In contrast to the previous experiments discussed above, it is important to highlight that NMR signal in these measurements arises both from the water and the gaseous hydrocarbon content. The sample temperature was reduced from $20^{\circ} \mathrm{C}$ to $3.5^{\circ} \mathrm{C}$ at $5.7^{\circ} \mathrm{C} /$ hour. In this case hydrate formation commenced at a temperature of approximately $11^{\circ} \mathrm{C}$. The mean hydrate formation rate was $0.004 \mathrm{ml} / \mathrm{min}\left(2.05 \times 10^{-4} \mathrm{~min}^{-1}\right.$ in terms of hydrate saturation with an initial rate of $1.17 \times 10^{-4} \mathrm{~min}^{-1}$ and a maximum rate of $6.67 \times 10^{-4} \mathrm{~min}^{-1}$ ) - this rate is within the ranges observed by Zhang et al. ${ }^{72}\left(6.6 \times 10^{-5}-7 \times 10^{-4} \mathrm{~min}^{-1}\right)$ and Zhang et al. ${ }^{55}\left(1.31 \times 10^{-4}\right.$ $\min ^{-1}$ ) albeit both used pure methane but for a similar particle size porous media host and initial water saturation. The hydrate formation curve presents a number of complex transitions, most prominently a comparatively slow initial period before a fast formation rate which has been observed previously for mixed gas compositions as demonstrated in literature. ${ }^{73,74}$ It has also been observed to occur in studies with pure methane hydrate ${ }^{75}$ and is often associated with a change (increase) in interfacial area between the gas and aqueous phase that results from the earlier hydrate formation. Figure 10 shows that residual water saturation was $1.3 \%$ when the hydrate formation was complete; this residual water was found to freeze upon the imposition of sub-zero temperatures. After approximately 115 hours the sample was heated and the initial water saturation signal returned fully. 


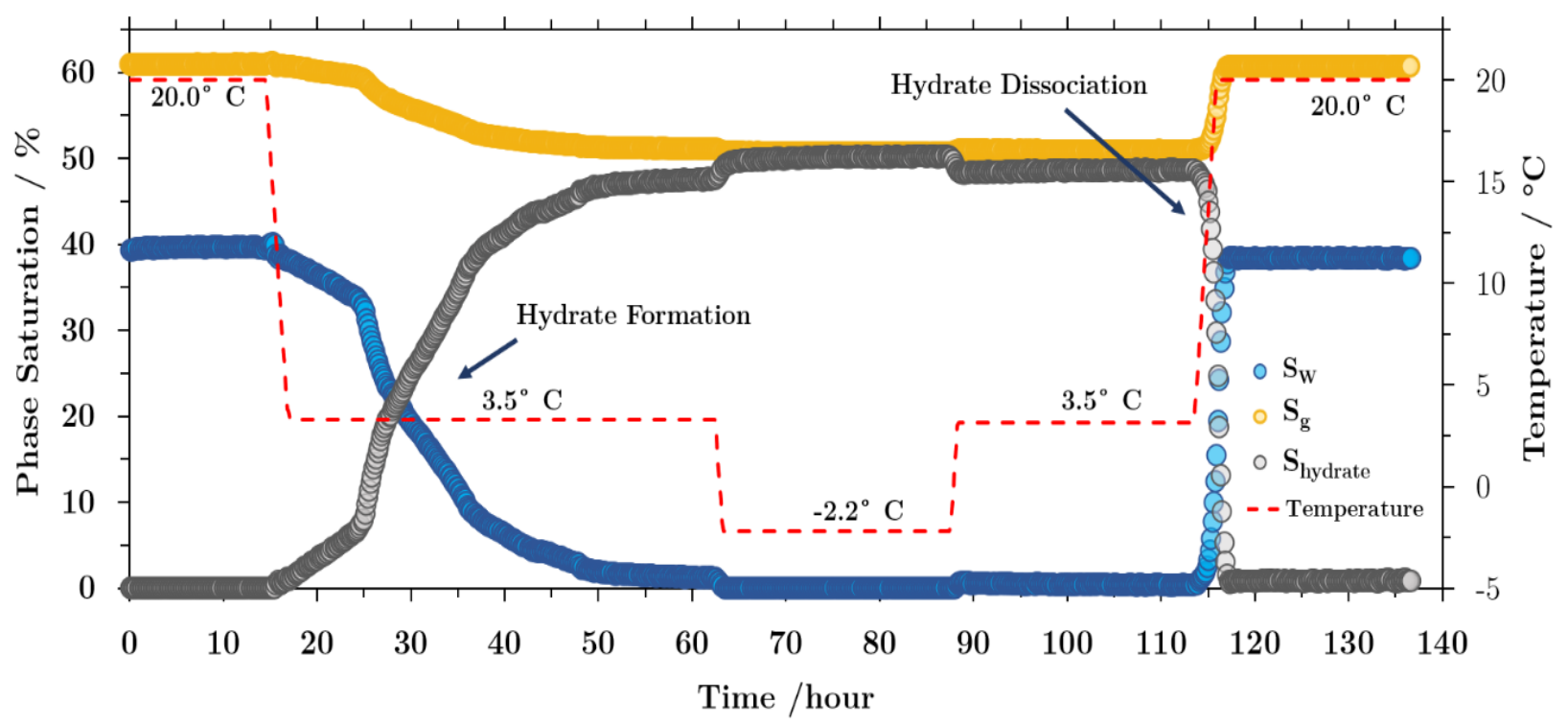

Figure 10. Phase saturations during the hydrate formation/dissociation experiment using methane and ethane (molar fractions $x_{\mathrm{CH}_{4}}=0.68$ and $x_{\mathrm{C}_{2} \mathrm{H}_{6}}=0.32$ ).

Figure 11 shows the corresponding $T_{2}$ relaxation time distributions as well as 1-D MRI SPRITE profiles for hydrate formation and dissociation as a function of time from this methane + ethane mixture. In agreement with the $\mathrm{CO}_{2}$ hydrate data presented above, two distinct $T_{2}$ populations are evident - however these are a combination of the original pore size distribution convoluted with the different fluids providing signal: residual water and the hydrocarbon gas. Consequentially allocation to a specific pore size is not possible although the following observations can however be made. Once hydrate formation commenced, signal loss occurred from both peaks whose mean $T_{2}$ values remained essentially unchanged. A single peak was left when hydrate formation was complete - this was evenly distributed through the packing and resulted from the hydrocarbon gas content. Preferential formation of hydrate in the lower region of the packing is evident and results in a comparatively flat signal profile that gradually decreases. Future work will focus on deconvolution of this rich $T_{2}$ data from both phases via the acquisition of $2 \mathrm{D} T_{2}-D$ data (where $D$ is the self-diffusion coefficient), as well as on delivering a more homogeneous initial water saturation in the vertical direction. 

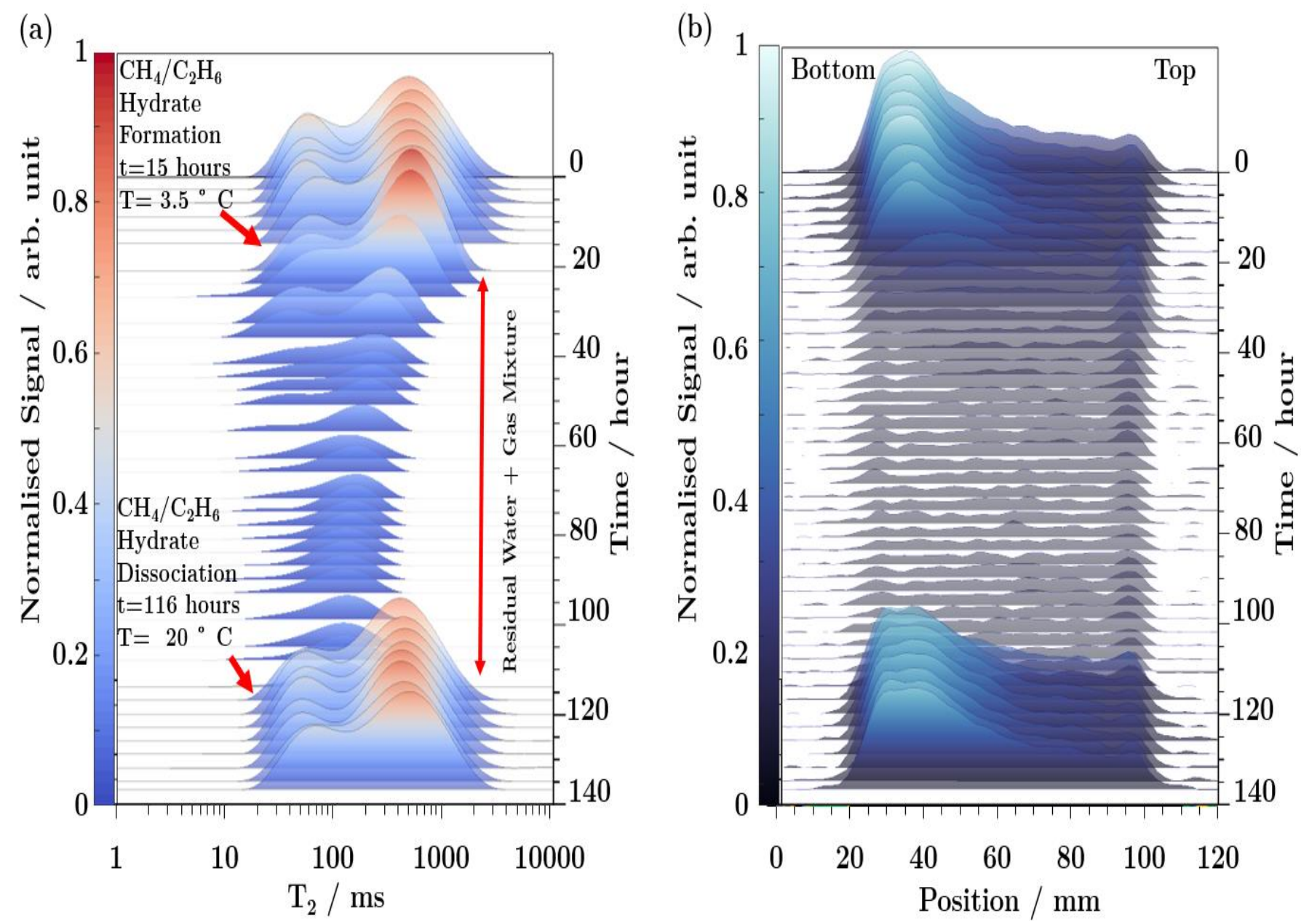

Figure 11. (a) Evolution of $T_{2}$ relaxation time distributions and (b) 1-D SPRITE profiles during the gas hydrate formation/dissociation experiment using a methane and ethane mixture (molar fractions $x_{\mathrm{CH}_{4}}=0.68$ and $x_{\mathrm{C}_{2} \mathrm{H}_{6}}=0.32$ ).

\section{CONCLUSIONS}

A novel hydrate sample holder has been constructed that is compatible with benchtop NMR/MRI hardware typically applied for rock core analysis. The unique central cooling channel operating at ambient pressure allows temperature to be controlled without affecting the operation of the magnet system. Mechanical integrity and the temperature distribution through the sample holder was investigated using 3D FEM and found to be satisfactory over the process conditions required. By way of demonstration, hydrate formation and dissociation in a partially saturated random packing of glass ballotini was successfully performed using both $\mathrm{CO}_{2}$ and a mixture of $\mathrm{CH}_{4}$ and $\mathrm{C}_{2} \mathrm{H}_{6}$ as the hydrate formers. In these experiments phase saturations (liquid water, gas, hydrate), pore size distributions and axial concentration profiles (both of the residual unsolidified water) were quantified through a hydrate formationdissociation cycle. Future work will consider the use of more sophisticated multi-dimensional 
$T_{2}-D$ measurements to better resolve the signal contribution from the residual water and the hydrocarbon gas/fluid phase, and detail a series of experiments using these techniques together with the hardware developed to monitor the gradual replacement of $\mathrm{CH}_{4}$ hydrates by $\mathrm{CO}_{2}$ in a range of porous media support structures.

\section{ACKNOWLEDGEMENTS}

This work was funded by the Australian Research Council through Discovery Project: DP170101108. 


\section{REFERENCES}

(1) Collett, T.; Bahk, J.J.; Baker, R.; Boswell, R.; Divins, D.; Frye, M.; Goldberg, D.; Husebø, J.; Koh, C.; Malone, M.; Morell, M.; Myers, G.; Shipp, C.; Torres, M. Methane Hydrates in Nature-Current Knowledge and Challenges. J. Chem. Eng. Data 2014, 60 (2), 319-329.

(2) Koh, C. A.; Sum, A. K.; Sloan, E. D. State of the art: Natural gas hydrates as a natural resource. J. Nat. Gas Sci. Eng. 2012, 8, 132-138.

(3) Makogon, Y. F. Natural gas hydrates - A promising source of energy. J. Nat. Gas Sci. Eng. 2010, 2 (1), 49-59.

(4) Sloan Jr, E. D.; Koh, C. A.; Koh, C. A. Clathrate Hydrates of Natural Gases; CRC Press, Boca Raton, FL, USA, 2007.

(5) Rajput, S.; Thakur, N. K. Chapter 2 - Generation of Methane in Earth. In Geological Controls for Gas Hydrate Formations and Unconventionals, Elsevier: 2016, 35-68.

(6) Hassanpouryouzband, A.; Joonaki, E.; Vasheghani Farahani, M.; Takeya, S.; Ruppel, C.; Yang, J.; English, N. J.; Schicks, J. M.; Edlmann, K.; Mehrabian, H.; Aman, Z. M.; Tohidi,

B. Gas hydrates in sustainable chemistry. Chem. Soc. Rev. 2020, 49, 5225-5309. DOI: 10.1039/C8CS00989A

(7) Hauge, L. P.; Birkedal, K. A.; Ersland, G.; Graue, A. Methane Production from Natural Gas Hydrates by $\mathrm{CO}_{2}$ Replacement Review of Lab Experiments and Field Trial. In SPE Bergen One Day Seminar, Bergen, Norway, April 2, 2014; Paper SPE 169198-MS.

(8) Merey, S.; Al-Raoush, R. I.; Jung, J.; Alshibli, K. A. Comprehensive Literature Review on $\mathrm{CH}_{4}-\mathrm{CO}_{2}$ Replacement in Microscale Porous Media. J. Pet. Sci. Eng. 2018, 171, 48-62.

(9) Boswell, R.; Schoderbek, D.; Collett, T. S.; Ohtsuki, S.; White, M.; Anderson, B. J. The Iggnik Sikumi Field Experiment, Alaska North Slope: Design, Operations, and Implications for $\mathrm{CO}_{2}-\mathrm{CH}_{4}$ Exchange in Gas Hydrate Reservoirs. Energy Fuels 2016, 31 (1), 140-153.

(10) Stanwix, P. L.; Rathnayake, N. M.; de Obanos, F. P. P.; Johns, M. L.; Aman, Z. M.; May, E. F. Characterising thermally controlled $\mathrm{CH}_{4}-\mathrm{CO}_{2}$ hydrate exchange in unconsolidated sediments. Energy Environ. Sci. 2018, 11 (7), 1828-1840.

(11) Komatsu, H.; Ota, M.; Smith, R. L.; Inomata, H. Review of $\mathrm{CO}_{2}-\mathrm{CH}_{4}$ clathrate hydrate replacement reaction laboratory studies - Properties and kinetics. J. Taiwan Inst. Chem. Eng. 2013, 44 (4), 517-537. 
(12) Koh, D. Y.; Kang, H.; Lee, J. W.; Park, Y.; Kim, S. J.; Lee, J.; Lee, J. Y.; Lee, H. Energy-efficient Natural Gas Hydrate Production Using Gas Exchange. Appl. Energy 2016, $162,114-130$.

(13) Schicks, J. M.; Luzi, M.; Beeskow-Strauch, B. The Conversion Process of Hydrocarbon Hydrates into $\mathrm{CO}_{2}$ Hydrates and Vice Versa: Thermodynamic Considerations. J. Phys. Chem. A 2011, 115 (46), 13324-31.

(14) Falenty, A.; Qin, J.; Salamatin, A. N.; Yang, L.; Kuhs, W. F. Fluid Composition and Kinetics of the in Situ Replacement in $\mathrm{CH}_{4}-\mathrm{CO}_{2}$ Hydrate System. J. Phys. Chem. C 2016, 120 (48), 27159-27172.

(15) Xu, C. G.; Yan, R.; Fu, J.; Zhang, S. H.; Yan, K. F.; Chen, Z. Y.; Xia, Z. M.; Li, X. S. Insight into Micro-mechanism of Hydrate-based Methane Recovery and Carbon Dioxide Capture from Methane-carbon Dioxide Gas Mixtures with Thermal Characterization. Appl. Energy 2019, 239, 57-69.

(16) Mitchell, J.; Chandrasekera, T. C.; Holland, D. J.; Gladden, L. F.; Fordham, E. J. Magnetic Resonance Imaging in Laboratory Petrophysical Core Analysis. Phys. Rep. 2013, $526(3), 165-225$.

(17) Kleinberg, R. L.; Vinegar, H. J. NMR Properties of Reservoir Fluids. The Log Analyst 1996, 37 (06), 20-32.

(18) Ersland, G.; Husebø, J.; Graue, A.; Kvamme, B. Transport and Storage of $\mathrm{CO}_{2}$ in Natural Gas Hydrate Reservoirs. Energy Procedia 2009, 1 (1), 3477-3484.

(19) Zhao, Y.; Song, Y.; Liu, Y.; Liang, H.; Dou, B. Visualization and Measurement of $\mathrm{CO}_{2}$ Flooding in Porous Media Using MRI. Ind. Eng. Chem. Res. 2011, 50 (8), 4707-4715.

(20) Li, M.; Vashaee, S.; Romero-Zerón, L.; Marica, F.; Balcom, B. J. A Magnetic Resonance Study of Low Salinity Waterflooding for Enhanced Oil Recovery. Energy Fuels 2017, 31 (10), 10802-10811.

(21) Zecca, M.; Vogt, S. J.; Connolly, P. R. J.; May, E. F.; Johns, M. L. NMR Measurements of Tortuosity in Partially Saturated Porous Media. Transp. Porous Media 2018, 125 (2), 271288.

(22) Li, M.; Vogt, S. J.; May, E. F.; Johns, M. L. In Situ $\mathrm{CH}_{4}-\mathrm{CO}_{2}$ Dispersion Measurements in Rock Cores. Transp. Porous Media 2019, 129 (1), 75-92.

(23) Liu, G. R.; Quek, S. S., The Finite Element Method : A Practical Course. Elsevier Science \& Technology: Oxford, UK, 2013.

(24) Chen, X.; Liu, Y., Finite Element Modeling and Simulation with ANSYS Workbench. CRC Press LLC: Bosa Roca, USA, 2014. 
(25) McPhee, C.; Reed, J.; Zubizaretta, I., Core Analysis: a Best Practice Guide. Elsevier: Oxford, Netherlands, 2015.

(26) Coates, G. R.; Xiao, L.; Prammer, M. G. NMR Logging: Principles and Applications; Haliburton Energy Services: Houston, TX, 1999.

(27) Meiboom, S.; Gill, D. Modified Spin-Echo Method for Measuring Nuclear Relaxation Times. Rev. Sci. Instrum. 1958, 29 (8), 688-691.

(28) Kleinberg, R. L. Nuclear Magnetic Resonance Pore-Scale Investigation of Permafrost and Gas Hydrate Sediments. J. Geol. Soc. (London, U. K.) 2006, 267 (1), 179.

(29) Freedman, R.; Heaton, N.; Flaum, M.; Hirasaki, G. J.; Flaum, C.; Hürlimann, M. Wettability, Saturation, and Viscosity From NMR Measurements. Soc. Pet. Eng. J. 2003, 8 (04), 317-327.

(30) Connolly, P. R. J.; Yan, W.; Zhang, D.; Mahmoud, M.; Verrall, M.; Lebedev, M.; Iglauer, S.; Metaxas, P. J.; May, E. F.; Johns, M. L. Simulation and Experimental Measurements of Internal Magnetic Field Gradients and NMR Transverse Relaxation Times $\left(T_{2}\right)$ in Sandstone Rocks. J. Pet. Sci. Eng. 2019, 175, 985-997.

(31) Li, M.; Romero-Zerón, L.; Marica, F.; Balcom, B. J. Polymer Flooding Enhanced Oil Recovery Evaluated with Magnetic Resonance Imaging and Relaxation Time Measurements. Energy Fuels 2017, 31 (5), 4904-4914.

(32) Muir, C. E.; Petrov, O. V.; Romanenko, K. V.; Balcom, B. J. Measuring Miscible Fluid Displacement in Porous Media with Magnetic Resonance Imaging. Water Resour. Res. 2014, 50 (3), 1859-1868.

(33) Honari, A.; Vogt, S. J.; May, E. F.; Johns, M. L. Gas-Gas Dispersion Coefficient Measurements Using Low-Field MRI. Transp. Porous Media 2015, 106 (1), 21-32.

(34) Mitchell, J.; Staniland, J.; Chassagne, R.; Fordham, E. J. Quantitative In Situ Enhanced Oil Recovery Monitoring Using Nuclear Magnetic Resonance. Transp. Porous Media 2012, 94 (3), 683-706.

(35) Balcom, B. J.; Macgregor, R. P.; Beyea, S. D.; Green, D. P.; Armstrong, R. L.; Bremner, T. W. Single-Point Ramped Imaging with $T_{1}$ Enhancement (SPRITE). J. Magn. Reson., Ser. A 1996, 123 (1), 131-134.

(36) Lee, S.; Cha, I.; Seo, Y. Phase Behavior and ${ }^{13}$ C NMR Spectroscopic Analysis of the Mixed Methane + Ethane + Propane Hydrates in Mesoporous Silica Gels. J. Phys. Chem. B 2010, 114 (46), 15079-15084. 
(37) Kang, S. P.; Lee, J. W.; Ryu, H. J. Phase Behavior of Methane and Carbon Dioxide Hydrates in Meso- and Macro-sized Porous Media. Fluid Phase Equilib. 2008, 274 (1-2), 6872.

(38) Lee, S.; Park, S.; Lee, Y.; Seo, Y. Thermodynamic and ${ }^{13}$ C NMR Spectroscopic Verification of Methane-Carbon Dioxide Replacement in Natural Gas Hydrates. Chem. Eng. J. 2013, 225, 636-640.

(39) Cha, M.; Shin, K.; Lee, H.; Moudrakovski, I. L.; Ripmeester, J. A.; Seo, Y. Kinetics of Methane Hydrate Replacement with Carbon Dioxide and Nitrogen Gas Mixture Using in Situ NMR Spectroscopy. Environ. Sci. Technol. 2015, 49 (3), 1964-1971.

(40) Lee, Y.; Kim, Y.; Seo, Y. Enhanced $\mathrm{CH}_{4}$ Recovery Induced via Structural Transformation in the $\mathrm{CH}_{4} / \mathrm{CO}_{2}$ Replacement That Occurs in sH Hydrates. Environ. Sci. Technol. 2015, 49 (14), 8899-8906.

(41) Seo, Y. j.; Park, S.; Kang, H.; Ahn, Y. H.; Lim, D.; Kim, S. J.; Lee, J.; Lee, J. Y.; Ahn, T.; Seo, Y.; Lee, H. Isostructural and Cage-Specific Replacement Occurring in sII Hydrate with External $\mathrm{CO}_{2} / \mathrm{N}_{2}$ Gas and its Implications for Natural Gas Production and $\mathrm{CO}_{2}$ Storage. Appl. Energy 2016, 178, 579-586.

(42) Lee, Y.; Choi, W.; Seo, Y. j.; Lee, J. Y.; Lee, J.; Seo, Y. Structural Transition Induced by Cage-dependent Guest Exchange in $\mathrm{CH}_{4}+\mathrm{C}_{3} \mathrm{H}_{8}$ Hydrates with $\mathrm{CO}_{2}$ Injection for Energy Recovery and $\mathrm{CO}_{2}$ Sequestration. Appl. Energy 2018, 228, 229-239.

(43) Baldwin, B. A.; Moradi-Araghi, A.; Stevens, J. C. Monitoring Hydrate Formation and Dissociation in Sandstone and Bulk with Magnetic Resonance Imaging. Magn. Reson. Imaging 2003, 21 (9), 1061-1069.

(44) Bagherzadeh, S. A.; Moudrakovski, I. L.; Ripmeester, J. A.; Englezos, P. Magnetic Resonance Imaging of Gas Hydrate Formation in a Bed of Silica Sand Particles. Energy Fuels 2011, 25 (7), 3083-3092.

(45) Husebø, J.; Ersland, G.; Graue, A.; Kvamme, B. Effects of Salinity on Hydrate Stability and Implications for Storage of $\mathrm{CO}_{2}$ in Natural Gas Hydrate Reservoirs. Energy Procedia 2009, $1(1), 3731-3738$.

(46) Kvamme, B.; Graue, A.; Buanes, T.; Kuznetsova, T.; Ersland, G. Storage of $\mathrm{CO}_{2}$ in Natural Gas Hydrate Reservoirs and the Effect of Hydrate as an Extra Sealing in Cold Aquifers. Int. J. Greenhouse Gas Control 2007, 1 (2), 236-246.

(47) Kvamme, B.; Graue, A.; Aspenes, E.; Kuznetsova, T.; Gránásy, L.; Tóth, G.; Pusztai, T.; Tegze, G. Kinetics of Solid Hydrate Formation by Carbon Dioxide: Phase Field Theory of 
Hydrate Nucleation and Magnetic Resonance Imaging. Phys. Chem. Chem. Phys. 2004, 6 (9), 2327-2334.

(48) Ersland, G.; Husebø, J.; Graue, A.; Baldwin, B. A.; Howard, J.; Stevens, J. Measuring Gas Hydrate Formation and Exchange with $\mathrm{CO}_{2}$ in Bentheim Sandstone using MRI Tomography. Chem. Eng. J. 2010, 158 (1), 25-31.

(49) Song, Y.; Zhang, L.; Lv, Q.; Yang, M.; Ling, Z.; Zhao, J. Assessment of Gas Production from Natural Gas Hydrate Using Depressurization, Thermal Stimulation and Combined Methods. RSC Adv. 2016, 6 (53), 47357-47367.

(50) Kleinberg, R. L.; Flaum, C.; Griffin, D. D.; Brewer, P. G.; Malby, G. E.; Peltzer, E. T.; Yesinowski, J. P. Deep Sea NMR: Methane Hydrate Growth Habit in Porous Media and its Relationship to Hydraulic Permeability, Deposit Accumulation, and Submarine Slope Stability. J. Geophys. Res.: Solid Earth 2003, 108 (B10).

(51) Minagawa, H.; Egawa, K.; Sakamoto, Y.; Komai, T.; Tenma, N.; Narita, H., Characterization of Hydraulic Permeability of Methane-Hydrate-Bearing Sediment Estimated by $T_{2}$-Distribution of Proton NMR. In The Twenty-second International Offshore and Polar Engineering Conference, International Society of Offshore and Polar Engineers: Rhodes, Greece, 2012; p 5.

(52) Minagawa, H.; Nishikawa, Y.; Ikeda, I.; Miyazaki, K.; Takahara, N.; Sakamoto, Y.; Komai, T.; Narita, H. Characterization of Sand Sediment by Pore Size Distribution and Permeability Using Proton Nuclear Magnetic Resonance Measurement. J. Geophys. Res.: Solid Earth 2008, 113 (B7).

(53) Komai, T.; Sakamoto, Y.; Nakashima, Y.; Takahara, N.; Minagawa, H.; Tenma, N., NMR Measurement and Analysis of Porosity and Permeability for Hydrate-bearing Sediments. In Eighth ISOPE Ocean Mining Symposium, International Society of Offshore and Polar Engineers: Chennai, India, 2009; p 6.

(54) Shakerian, M.; Afrough, A.; Vashaee, S.; Marica, F.; Zhao, Y.; Zhao, J.; Song, Y.; Balcom, B. J. Direct Measurement of Pore Gas Pressure and Water/Gas Phase Transitions during Methane Hydrate Dissociation. Mar. Pet. Geol. 2020, 116.

(55) Zhang, Y.; Zhao, Y.; Lei, X.; Yang, M.; Zhang, Y.; Song, Y. Quantitatively Study on Methane Hydrate Formation/Decomposition Process in Hydrate-Bearing Sediments Using Low-Field MRI. Fuel 2020, 262.

(56) Bohne, D.; Fischer, S.; Obermeier, E. Thermal-Conductivity, Density, Viscosity, and Prandtl-Numbers of Ethylene Glycol-Water Mixtures. Phys. Chem. Chem. Phys. 1984, 88 (8), 739-742. 
(57) Tuma, P.; Knoll, S. A Comparison of Fluorinated and DI/Glycol Heat Transfer Fluids; Solid State Technology: Ossipee, NH, 2003; Document ID 866-772-5108.

(58) Tuma, P.; Tousignant, L. Reducing Emissions of PFC Heat Transfer Fluids. In SEMI Technical Symposium: Innovations in Semiconductor Manufacturing 3M: SEMICON®West, San Francisco, CA, 2001.

(59) Bauccio, M. ASM Engineered Materials Reference Book. 2nd ed.; ASM International, OH, USA, 1994.

(60) Bijwe, J.; Sen, S.; Ghosh, A. Influence of PTFE Content in PEEK-PTFE Blends on Mechanical Properties and Tribo-Performance in Various Wear Modes. Wear 2005, 258 (10), 1536-1542.

(61) Garcia-Gonzalez, D.; Rodriguez-Millan, M.; Rusinek, A.; Arias, A. Investigation of Mechanical Impact Behavior of Short Carbon-Fiber-Reinforced PEEK Composites. Composite Structures 2015, 133, 1116-1126.

(62) Kurtz, S. M. PEEK Biomaterials Handbook; Elsevier: Oxford, UK, 2012.

(63) Subramanian, S.; Kini, R. A.; Dec, S. F.; Sloan, E. D. Evidence of Structure II Hydrate Formation from Methane + Ethane Mixtures. Chem. Eng. Sci. 2000, 55 (11), 1981-1999.

(64) Sun, Q.; Kang, Y. T. Review on $\mathrm{CO}_{2}$ Hydrate Formation/Dissociation and its Cold Energy Application. Renewable Sustainable Energy Rev. 2016, 62, 478-494.

(65) Webber, J. B. W. Characterising Porous Media. Ph.D. Thesis, University of Kent, Canterbury, UK, 2000.

(66) Luo, Z. X.; Paulsen, J.; Song, Y. Q. Robust Determination of Surface Relaxivity from Nuclear Magnetic Resonance DT2 Measurements. J. Magn. Reson. 2015, 259, 146-52.

(67) Perepukhov, A. M.; Kishenkov, O. V.; Gudenko, S. V.; Maksimychev, A. V.; Aleksandrov, D. A.; Men'shikov, L. I.; Tkachenko, S. I. Specific Features of Proton NMR Relaxation of Hydrocarbons and Water in the Pore Space of Silicates. Russ. J. Phys. Chem. B 2014, 8 (3), 284-292.

(68) Yang, M.; Song, Y.; Zhao, Y.; Liu, Y.; Jiang, L.; Li, Q. MRI Measurements of $\mathrm{CO}_{2}$ Hydrate Dissociation Rate in a Porous Medium. Magn. Reson. Imaging 2011, 29 (7), 10071013.

(69) Cheng, C.; Zhao, J.; Song, Y.; Zhu, Z.; Liu, W.; Zhang, Y.; Yang, M.; Yu, X. In-situ Observation for Formation and Dissociation of Carbon Dioxide Hydrate in Porous Media by Magnetic Resonance Imaging. Sci. China: Earth Sci. 2013, 56 (4), 611-617. 
(70) Yang, M.; Song, Y.; Jiang, L.; Zhu, N.; Liu, Y.; Zhao, Y.; Dou, B.; Li, Q. CO 2 Hydrate Formation and Dissociation in Cooled Porous Media: A Potential Technology for $\mathrm{CO}_{2}$ Capture and Storage. Environ. Sci. Technol. 2013, 47 (17), 9739-9746.

(71) Yang, S. H. B.; Babu, P.; Chua, S. F. S.; Linga, P. Carbon Dioxide Hydrate Kinetics in Porous Media with and without Salts. Appl. Energy 2016, 162, 1131-1140.

(72) Zhang, L.; Sun, L.; Sun, M.; Lv, X.; Dong, H.; Miao, Y.; Yang, L.; Song, Y.; Zhao, J. Analyzing Spatially and Temporally Visualized Formation Behavior of Methane Hydrate in Unconsolidated Porous Media. Magn. Reson. Imaging 2019, 61, 224-230.

(73) Veluswamy, H. P.; Bhattacharjee, G.; Liao, J.; Linga, P. Macroscopic Kinetic Investigations on Mixed Natural Gas Hydrate Formation for Gas Storage Application. Energy Fuels 2020.

(74) Kumar, R.; Linga, P.; Moudrakovski, I.; Ripmeester, J. A.; Englezos, P. Structure and kinetics of gas hydrates from methane/ethane/propane mixtures relevant to the design of natural gas hydrate storage and transport facilities. AIChE J 2008, 54 (8), 2132-2144.

(75) Akhfash, M.; Boxall, J.A.; Aman, Z.M.; Johns, M.L.; May, E.F. Hydrate Formation and Particle Distributions in Gas-Water Systems. Chem. Eng. Sci. 2013, 104, 177-188. 